\title{
EL CATASTRO, LA ESTADÍSTICA Y MARTÍN DE GARAY EN LA COMUNIDAD DE MADRID, 1817-1820
}

Miguel Ángel Bringas Gutiérrez

Universidad de Cantabria

bringasma@unican.es

ORCID iD: https://orcid.org/0000-0002-6813-2857

íñigo del Mazo Durango

Universidad de Cantabria

inigodzdurango@gmail.com

ORCID iD: https://orcid.org/0000-0001-7692-2499

\section{Guillermo Mercapide Argüello}

Universidad de Cantabria gmerkapide@gmail.com

ORCID iD: https://orcid.org/0000-0001-6170-6961

Ángel Ignacio Aguilar Cuesta

Universidad Internacional Valenciana

angelignacio.aguilar@campusviu.es

ORCID iD: https://orcid.org/0000-0003-3240-0810

Recibido: 12/10/2020; Aceptado: 10/04/2021; Publicado: 17/06/2021

Cómo citar este artículo/citation: Bringas Gutiérrez, Miguel Ángel; Mazo Durango del, Íñigo; Mercapide Argüello, Guillermo y Aguilar Cuesta, Ángel Ignacio (2021). El catastro, la estadística y Martín de Garay en la Comunidad de Madrid, 1817-1820. Estudios Geográficos, 82 (290), e064. https://doi.org/10.3989/estgeogr.202076.076

Resumen: El objetivo de este trabajo es analizar el proceso de gestación de la documentación catastral y estadística producida por la reforma fiscal de Martín de Garay en la provincia de Madrid entre 1817 y 1820. Esta documentación estaba formada por los Apeos y valuaciones generales del capital y productos específicos de todas las tierras, edificios y propiedades que son un catastro o paracatastro y los Cuadernos generales de la riqueza que son las descripciones estadísticas de las producciones e ingresos agrarios elaborados en cada una de las villas, pueblos, lugares y despoblados madrileños durante esos años. Las operaciones emprendidas por las distintas juntas implicadas en su elaboración dieron como resultado que, al menos, los cuadernos generales de la riqueza de todos los pueblos y villas de Madrid se hubieran concluido en el verano de 1818. En la parte final del texto detallamos los fondos localizados, hasta el momento, en los archivos municipales de la Comunidad de Madrid y como este corpus documental debe formar parte del repertorio de fuentes geohistóricas disponibles a escala nacional.

Palabras clave: Apeo, Cuaderno General de la Riqueza, fuentes geohistóricas, Madrid, Martín de Garay, siglo XIX y geografía histórica.

\section{THE CADASTRE, STATISTICS AND MARTÍN DE GARAY IN THE COMMUNITY OF MADRID, 1817-1820}

Abstract: This work aims to analyze the process of development of land registry and statistical documentation Martín de Garay's tax reform produced in the province of Madrid in the period between 1817 and 1820 . These documents were to be composed of a cadastre (paracadastre in the strict sense) known as Surveying and general valuation of the capital and specific products of all lands, buildings and property. They encompassed also statistical depictions of all agrarian production and income, i.e. the General Logbooks of Wealth written at every single village, town and depopulated areas of Madrid at the time considered. The task was undertaken by several juntas and resulted in the completion of the General logbooks for every single village and town in the province by summer 1818 . A detailed list of all records located to the date in the Community of Madrid's archives is also included in this work. Lastly, we discuss the need for this documentary corpus to become available at a national level, with other national geohistorical sources.

Keywords: Surveying, General Logbooks of Wealth, Geohistorical sources, Madrid, Martín de Garay, 19th century, Historical geography 
"Martín de Garay [...] trajo al Ministerio todo un plan e idea completa para reformar la Hacienda pública [...]. Gozaba aquel señor de mucha fama [...] pero todos los hombres de mi tiempo, desde el Rey [...] hasta el último zascandil se pusieron en contra suya, y tuvo que salir del Ministerio ..."

Benito Pérez Galdós, La segunda casaca, 1876, p. 42

El objetivo de este trabajo es analizar el proceso de gestación y la descripción de los fondos históricos localizados relacionados con la documentación catastral y estadística producida por la reforma fiscal de Martín de Garay en la provincia de Madrid entre 1817 y 1820. ${ }^{1}$ Esta documentación conocida como la Estadística General del Reino está formada por los Apeos y valuaciones generales del capital y productos especificos de todas las tierras, edificios y propiedades y los Cuadernos generales de la riqueza redactados en cada una de las villas, pueblos, lugares y despoblados madrileños durante esos años.

Los apeos son catastros textuales en los que se detallan las propiedades y bienes de todos los vecinos e instituciones existentes en cada pueblo pudiéndose, en muchos casos, georreferenciarse toda esta información, aunque los apeos no incluyan ninguna representación gráfica de las fincas rústicas ni urbanas por lo que debemos referirnos a estos apeos como catastros literales o paracatastro. ${ }^{2}$ Por otro lado, los cuadernos generales de la riqueza recogen una completa descripción estadística de las producciones y los ingresos que tenían su origen en las distintas actividades económicas (agrícolas, ganaderas, oficios, comerciales, arriería, etc.) realizadas en cada uno de los núcleos de población ya fueran sus beneficiarios vecinos o forasteros. Ambos documentos complementan sus contenidos constituyendo una fuente geohistórica de enorme interés para abordar investigaciones desde los campos de la historia económica, la historia agraria y la geografía histórica en la España de principios del siglo XIX.

1 Esta investigación forma parte del Proyecto $I+D+i$ del Ministerio de Ciencia e Innovación PID2019-106735GBC21.

2 Sólo tenemos constancia de que los apeos de los 18 pueblos del partido de Granada fueran acompañados de sus respectivos mapas realizado por Francisco Dalmau y su equipo entre 1819 y 1820 aunque en las villas de Albolote, Atarfe y Calicasas no se llegaron a concluir. Dalmau (1820) p. 13 y García-Pulido (2016).

\section{LA REFORMA FISCAL DE MARTIN DE GARAY: EL ORIGEN DE UNA FUENTE GEOHISTÓRICA, 1817-1820}

Esta documentación tiene su origen en la reforma del sistema tributario español llevada a cabo por Martín de Garay y su equipo ante los graves problemas que atravesaba la Real Hacienda en las primeras décadas del siglo XIX. ${ }^{3}$ El Real Decreto de 30 de mayo de 1817 establecía dos tipos de impuestos: la Contribución General del Reino directa y proporcional sobre las rentas de las actividades económicas (agricultura, ganadería, oficios, etc.) del mundo rural y el Derechos de Puertas, un impuesto indirecto sobre el valor de las mercancías consumidas en las capitales de provincia y los puertos autorizados a comerciar con América. Martín de Garay fue cesado en septiembre de $1818^{4}$ pero sus planes de reforma fueron continuados por José Imaz Baquedano y posteriormente por Antonio González Salmón quien estuvo al frente del ministerio entre noviembre de 1819 y marzo de $1820 .{ }^{5}$ Ese mismo mes, Fernando VII fue obligado a jurar la Constitución de 1812 dando comienzo el Trienio Liberal en el cual se reabre la discusión sobre la necesidad de introducir profundos cambios en el ya obsoleto sistema recaudatorio de la hacienda española llegándose a promulgar una nueva reforma en 1821 (figura 1).

En la primavera de 1823 , Fernando VII es repuesto como monarca absolutista y un Real Decreto de 16 de febrero de 1824 deroga definitivamente la reforma de Martín de Garay de mayo de 1817 menos en lo referente a los Derechos de Puertas que se mantienen en las capitales de provincia, en los puertos habilitados y se amplía a los pueblos que tuviesen más de 15.000 habitantes. Se afirmaba en el preámbulo de este Real Decreto que los inconvenientes que había presentado el establecimiento de la Contribución General del Reino "cuyos repartimientos [...] han quedado incobrables y el deseo con que los contribuyentes se han decidido en favor de la antigua forma de contribuir", enseñaban lo peligroso

3 Martín de Garay fue el secretario de la Junta Central y formó parte del Consejo de Estado creado por las Cortes de Cádiz. Sobre su reforma y los orígenes de la fiscalidad contemporánea en España ver Hernández Andreu (2008). 4 La versión oficial apuntaba a que su sustitución fue debida a su "quebrantada salud". Carta del 14 de septiembre de 1818. Martín de Garay ejerció el cargo durante 21 meses toda una hazaña en los gobiernos de Fernando VII durante el Sexenio. Su biografía política ha sido estudiada por Alonso Garcés (2009).

5 José Imaz era Director General de Rentas y uno de los colaboradores más cercanos a Martín de Garay. 
FIGURA 1

SISTEMA GENERAL DE HACIENDA Y LA ESTADÍSTICA GENERAL DEL REINO. 1817-1820

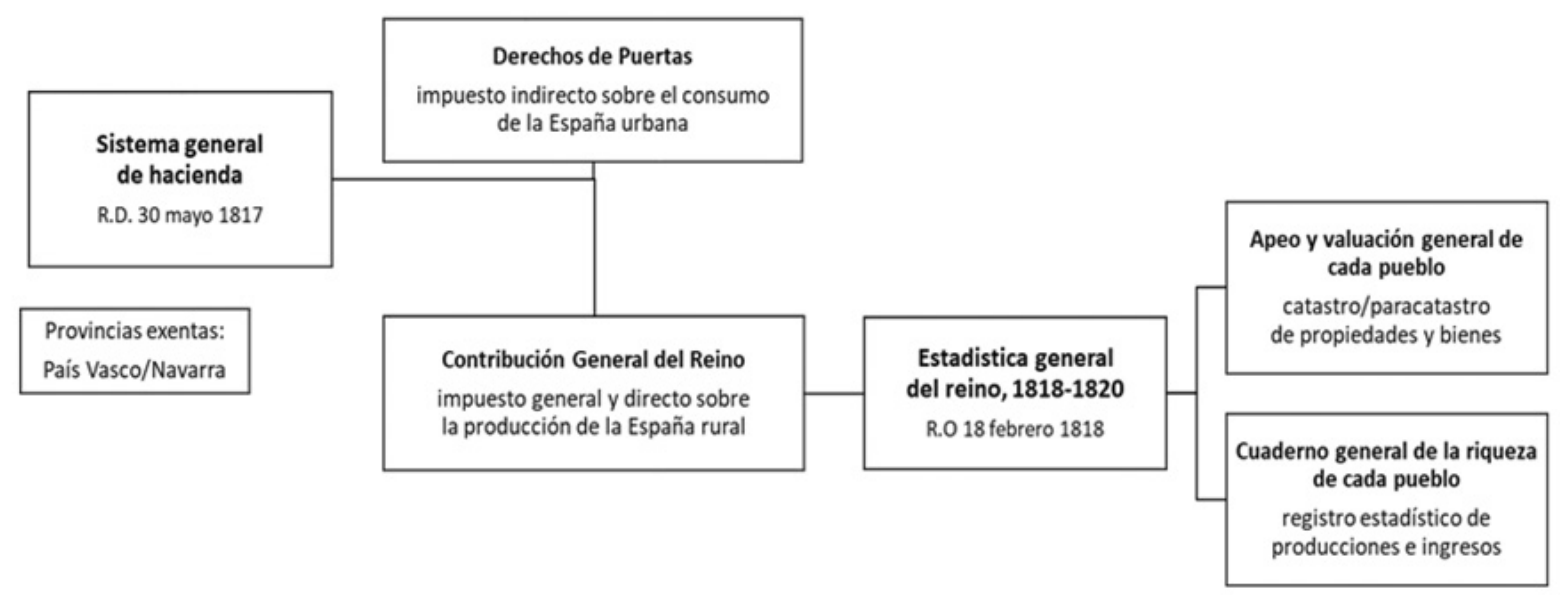

Fuente: elaboración propia.

que era cambiar las bases de los impuestos para edificar sobre otras un sistema nuevo. Por estas razones, aunque la realidad fuera mucho más compleja, "ha resuelto derogar [...] el real decreto dado por $\mathrm{Mi}$ en 30 de mayo de 1817, mandado que las rentas de la Corona vuelvan en cuanto antes sea posible al método que tenían antes de aquella fecha".

La Estadística General del Reino, compuesta por los apeos y los cuadernos, tenía la finalidad de proporcionar el soporte estadístico necesario para cuantificar la riqueza y su producto neto y así poder efectuar, de forma proporcionada, el reparto de la Contribución General del Reino entre todos los contribuyentes, tanto personas físicas como instituciones civiles y religiosas, de la España rural -que suponían el $85 \%$ de la población-, con la única excepción de las localidades pertenecientes a las cuatro provincias forales (Álava, Guipúzcoa, Navarra y Vizcaya) (figura 2).

Las duras críticas vertidas por numerosos diputados en la Cortes de Cádiz sobre los datos reunidos por los intendentes provinciales en 1799 , el conocido como Censo de frutos y manufacturas de España, mientras

FIGURA 2

ESTRUCTURA DE LA ESTADÍSTICA GENERAL DEL REINO: APEOS Y CUADERNOS, 1818-1820

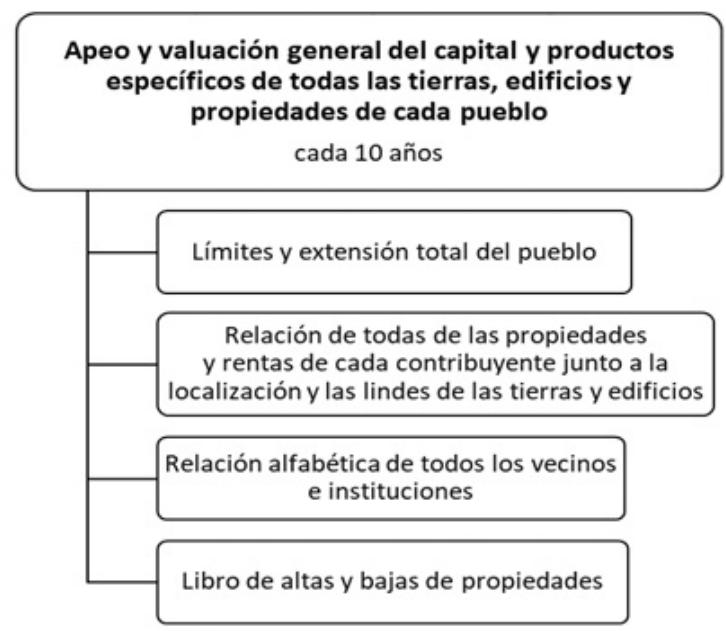

Fuente: elaboración propia.

Cuaderno general de la riqueza de cada pueblo cada año

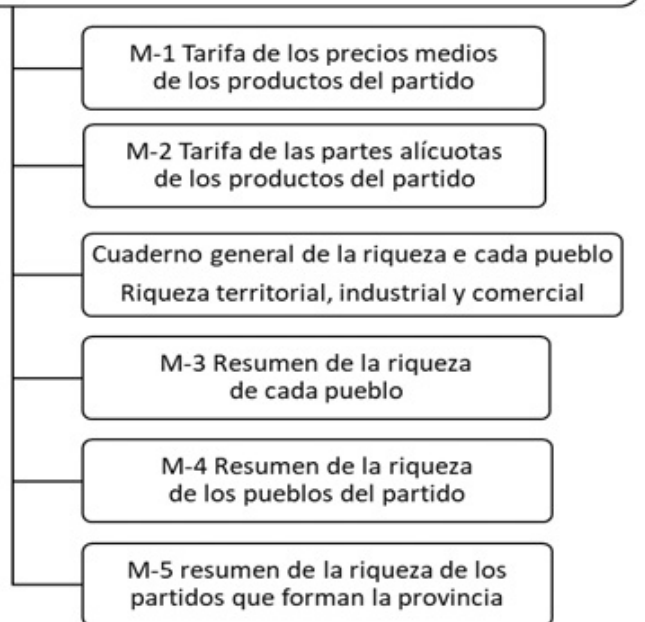


debatían la Contribución Directa ${ }^{6}$ obligaron a Martín de Garay a poner en marcha un ambicioso proyecto. Este tenía que dar como resultado la elaboración de un nuevo catastro y una nueva estadística que hiciera viable y creíble su reforma y el cobro de un impuesto directo y universal para lo cual no partía de cero sino que tuvo como fuente de inspiración lo que ya era una larga tradición reformista de los hacendistas españoles desde principios del siglo XVIII. ${ }^{7}$ Años después, Madoz afirmaría que Martin de Garay "llevado del mejor celo y conociendo la imperiosa necesidad" de realizar una estadística para el buen funcionamiento del sistema de hacienda "dio instrucciones, las más completas sin duda de cuantas se expidieron hasta su época, para conocer por ese medio la [...] riqueza de España" (Madoz, 1845/50, t. X, p. 589).

La formación de la estadística se convirtió en una cuestión prioritaria para Martín de Garay. Pero la vida de la estadística fue corta al igual que la vigencia de su reforma tributaria. En el Real Decreto de 30 de mayo de 1817 se dictaminaba que el reparto provincial de la contribución general no se efectuaría hasta contar con una estadística completa "fundada en el valor comparado de las producciones de todas las provincias", y el 18 de febrero de 1818 se ordena a las juntas de todos los pueblos que deben elaborar los apeos y valuaciones generales además de los cuadernos generales de la riqueza. A partir de ese momento, los intendentes provinciales reiterarán a las juntas de los partidos y locales en multitud de ocasiones, incluso con amenazas y graves sanciones, la necesidad de finalizar el catastro y la estadística a la mayor brevedad. Con la excusa de las dietas cobradas por los comisionados nombrados por las juntas provinciales y las de los partidos para comprobar y certificar las "descripciones de la riqueza" dadas por las juntas locales, el 28 de febrero de 1820 se decide que "cesen inmediatamente en este encargo", siendo los alcaldes quienes "continuarán dichas operaciones hasta su conclusión".

6 Las criticas aducidas por los diputados que se oponían a la implantación de la nueva contribución se referían a las numerosas confusiones entre productos y capitales, a la ausencia de datos fiables sobre el comercio y los problemas de desigualdad, tanto territorial como sectorial. López Castellano (1992) pp. 354-373 y 407-414.

7 Hernández Andreu (1972). Un real decreto de 13 de marzo de 1820 confirmaba que "la contribución general [...] reconoce los mismos principios que la directa que fijaron las Cortes extraordinarias en el de 13 de septiembre de 1813". Gaceta extraordinaria de Madrid, 14 de marzo de 1820.
Pero un mes más tarde, Fernando VII jura la constitución, y en junio de 1821, las nuevas autoridades del ministerio de hacienda decretan la realización de una nueva estadística territorial.

En menos de tres años, de febrero de 1818 a finales de 1820, Martín de Garay y sus sucesores intentaron llevar adelante la compleja empresa de elaborar un catastro textual y una estadística de la producción territorial, industrial y comercial en todas las provincias -menos cuatro- del territorio nacional.

¿Pero realmente se llegaron a elaborar estos apeos y cuadernos generales de la riqueza en la provincia de Madrid entre 1818 y 1820 ?

Este trabajo tiene la intención de responder a esta pregunta ante la falta de investigaciones que se hayan interesado por analizar esta cuestión. La historiografía, con carácter general, ha cuestionado en muchas ocasiones que la reforma fiscal de Martín de Garay hubiese dado algún resultado positivo. Incluso aquellos que han analizado su figura política no han puesto en valor la importancia de su proyecto estadístico. Pero la necesidad de distribuir la carga fiscal de la Contribución General del Reino sobre una base de información cuantificable condujo a la materialización documental de esta averiguación catastral/estadística en toda la provincia de Madrid y en muchos lugares de España a finales de la segunda década del siglo XIX (Bringas, 1994, 2003 y 2008; Bringas, Mazo y Mercapide, 2017 y Bringas, Mazo, Mercapide, García, Vallina y Aguilar, 2019).

\section{LA CONTRIBUCIÓN GENERAL DEL REINO EN LA COMUNIDAD DE MADRID, 1817-1820}

En el censo de Godoy de 1797 la población de Madrid llegaba a los 228.520 habitantes mientras que en el recuento efectuado por la policía en 1826 su número se había incrementado hasta los 297.812 lo que equivalía al 2,1 \% de la población española. Entre 1818 y 1820, la población madrileña se puede estimar en 276.800 habitantes de los cuales el $60,0 \%$ residían en la capital. Miñano estima su superficie en 3.395 $\mathrm{km}^{2}$ mientras que para Moreau de Jonnes su extensión es de 3.719 km² (Miñano, 1826/29, t. V, p. 309 y Moreau de Jonnes, 1835, pp. 22 y 41). ${ }^{8}$

¿Cómo se organizaba administrativa y fiscalmente el territorio de la, por entonces, provincia de Madrid?

8 Ambas cifras hay que tomarlas con las debidas precauciones. 
MAPA 1

LA PROVINCIA DE MADRID DE TOMÁS LÓPEZ, 1773

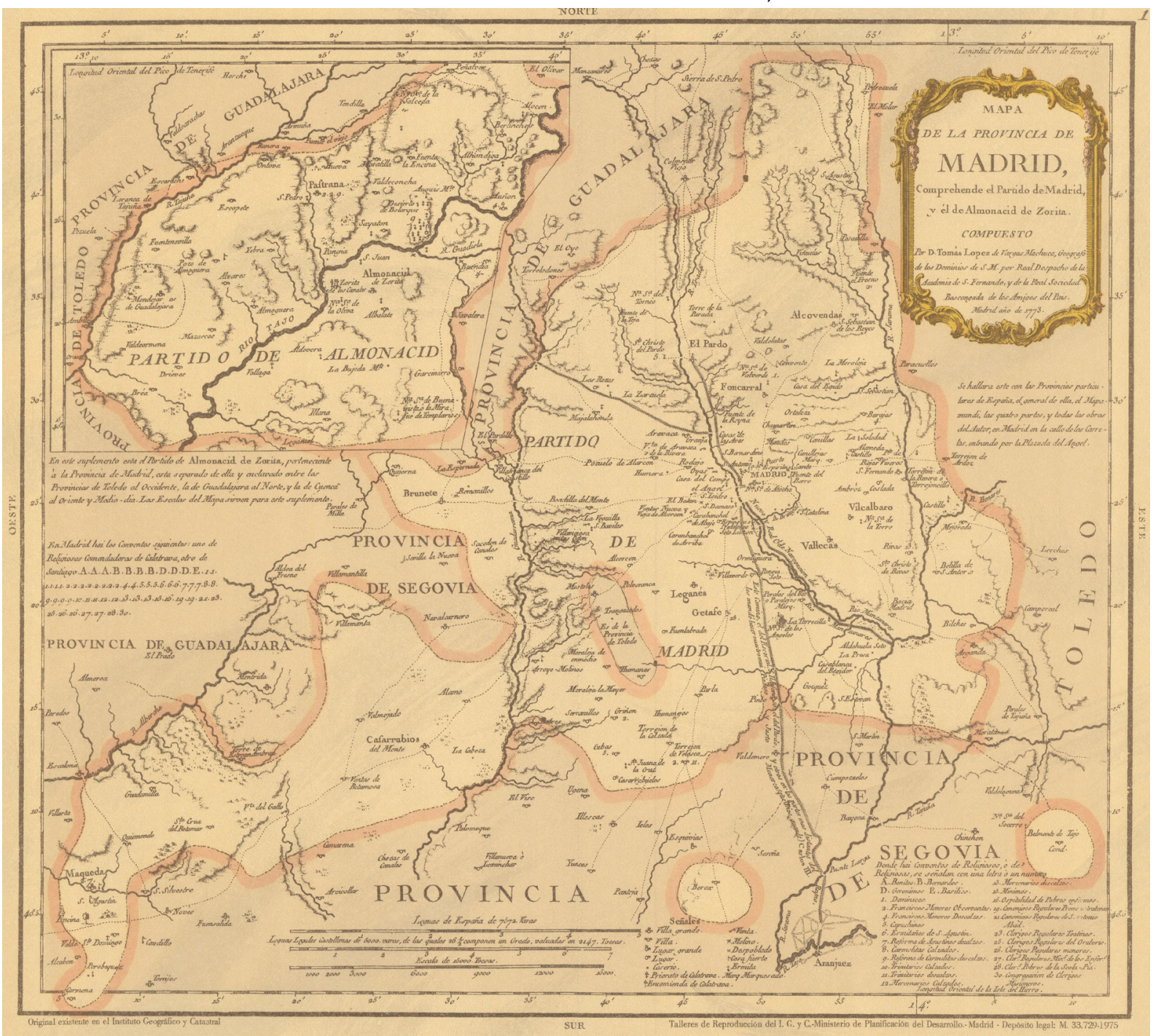

Fuente: Biblioteca virtual del patrimonio bibliográfico

Gracias al Catastro de Ensenada sabemos que, a mediados del siglo XVIII, esta provincia estaba constituida por 90 poblaciones, 58 de ellas con el rango de villas $y$ 32 con el de lugares, más 2 sitios reales y 7 despoblados (Camarero Bullón, 2001, v. 1, 20-30).

Desde finales del siglo XVIII y hasta 1833, el mapa de la provincia de Madrid experimenta notables cambios, ampliando su extensión (mapa 1). En 1789, su demarcación se configura en 4 partidos y 132 poblaciones. ${ }^{9}$ A partir de 1801 , la provincia de Madrid va

9 España dividida en provincias e intendencias,... (1789) v. I, pp. 370-373. adquiriendo un perfil más parecido al actual con la incorporación de enclaves de otras provincias: Guadalajara, Segovia, Toledo y los reales sitios de Aranjuez, El Escorial, El Pardo y San Fernando, hoy de Henares (Burgueño, 1997: 360).

La Gaceta de Madrid publicaba en septiembre de 1813 una relación de los 187 pueblos madrileños con las cantidades con las cuales debían tributar a la contribución directa establecida en las Cortes de Cádiz. ${ }^{10}$ Una circular de 3 de noviembre de 1817 organiza la

10 Gaceta de Madrid, 2 de septiembre de 1813, pp. 375-381. 
FIGURA 3

ORGANIGRAMA PARA LA EJECUCIÓN DE LA ESTADÍSTICA GENERAL DEL REINO EN LA COMUNIDAD DE MADRID, 1818-1820

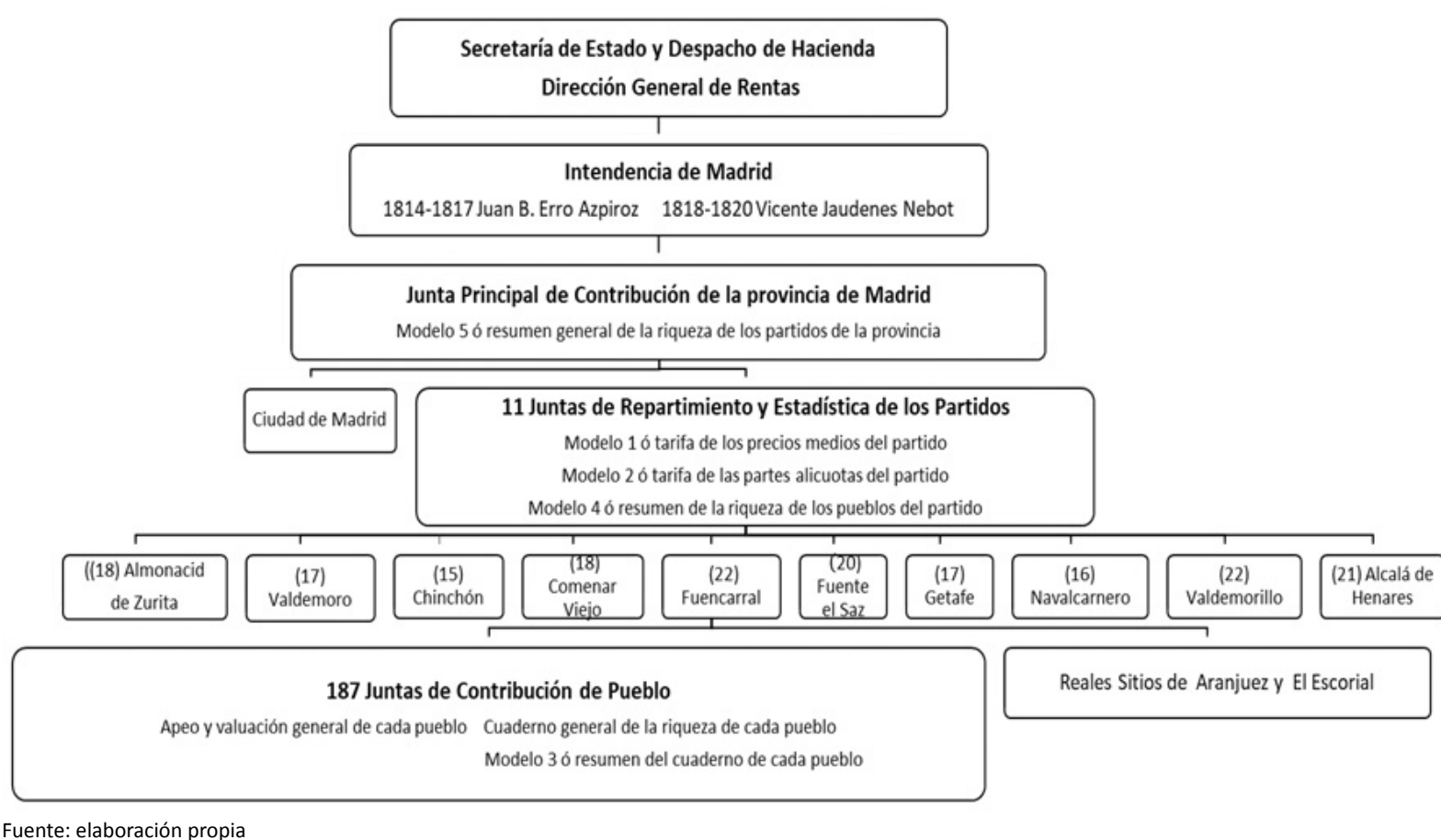

provincia de Madrid en 11 partidos (Alcalá de Henares, Almonacid de Zorita, Valdemoro, Chinchón, Colmenar Viejo, Fuencarral, Getafe, Navalcarnero, Valdemorillo, Fuente el Saz y Madrid) y otras tantas Juntas de Repartimiento y Estadística. Con la excepción del partido de Madrid que sólo comprende la ciudad, los demás partidos suman un total de 186 villas y lugares. ${ }^{11}$ Poco después, Miñano aseguraba que el total de poblaciones que componían la provincia de Madrid era de 187 distribuidas en 2 partidos (Miñano, 1826/29, t. V, p. 309). A mediados del siglo XIX, la provincia se organiza en 8 partidos con 197 ayuntamientos y 134 villas, 81 lugares y 1 ciudad (Madoz, 1845/50, t. X, pp. 546549). ${ }^{12}$

En Madrid, como en el resto de las provincias, la Dirección General de Rentas ordenó, en agosto de

11 Archivo municipal de Alcalá de Henares, leg. 642/1. En el Archivo de la Diputación Provincial de Burgos, sig. $1208 / 40$, se puede consultar el documento "la provincia de Burgos dividida en partidos para el establecimiento de la Contribución General del Reino según el decreto de 30 de mayo de 1817".

12 Estos 8 partidos sirvieron de base administrativa para el reparto de la contribución de 1848. Archivo municipal de Chinchón, sig. 8739.
1817, la creación de las Juntas de Repartimiento y Estadística de Partido dependientes de los intendentes provinciales a través de las Juntas Principales de Contribución de cada provincia. Los intendentes, nombrados por el Rey, disponían de amplios poderes para la recaudación de impuestos y el control de las autoridades provinciales y locales.

De 1814 a 1817, Juan Bautista de Erro ocupó la intendencia de Madrid para después ser destinado a Cataluña y a partir de enero de 1818 fue nombrado para este cargo Vicente Jaudenes Nebot hasta su sustitución a finales de $1820^{13}$. Las juntas de los partidos estaban compuestas por un representante de la Iglesia y tres personas legas que recibirán órdenes directamente de la junta principal por medio del intendente, siendo este el órgano de comunicación entre estas y las juntas de los pueblos (figura 3).

13 El 23 de enero de 1818, Jaudenes envía una misiva a todos los pueblos de Madrid anunciando que ha sido nombrado Intendente y solicitando de ellos que le "ayuden cumpliendo con energía y prontitud las órdenes que les comunique" para no tener que "emplear la autoridad que el Rey me tiene confiada". Archivo municipal de Chinchón, sig. 13063. 
En materia estadística su trabajo consistía en calcular los precios medios de los productos (modelo 1) y sus costes de producción (modelo 2) además de hacer el resumen de la riqueza del partido (modelo 4). Pero la parte fundamental de la ejecución de la estadística recaía en las juntas locales formadas por el corregidor o el alcalde, el cura párroco, el regidor decano, el síndico del común y el secretario del ayuntamiento. Ellas eran las encargadas de redactar los apeos o libros padrones cada diez años (figura 4) y anualmente los cuadernos generales de la riqueza (figura 5) y su resumen (modelo 3) (figura 6).

Las juntas principales de cada provincia reunían toda la información sobre la riqueza bruta y neta que le habían facilitado las juntas de los partidos y procedían a la igualación y el reparto del cupo de la contribución.

\section{FIGURA 4}

TRANSCRIPCIÓN DE UNA PÁGINA DEL APEO DE PARACUELLOS DEL JARAMA, 1819

\begin{tabular}{|c|c|}
\hline Juliana Herrreros & \\
\hline $\begin{array}{l}\text { Tiene una casa en calle Real que linda por el oriente con un } \\
\text { solar y por poniente con casa de Cosme Herreros su valor }\end{array}$ & 6000 \\
\hline $\begin{array}{l}\text { Otra casa sita en la calle de Burgos linda por el oriente con otra } \\
\text { casa de María Herreros y con la dicha calle y solares su valor }\end{array}$ & 2000 \\
\hline Tierras & \\
\hline $\begin{array}{l}\text { Una tierra de tercera calidad en el sitio que llaman la Granja } \\
\text { sembradura de siete fanegas, linda por el Barranco de } \\
\text { Bortivañez y con la Raya del termino de Velvis la que intitulan } \\
\text { la tierra de la mano regulando su valor en }\end{array}$ & 560 \\
\hline $\begin{array}{l}\text { Otra tierra situada en el paraje que titulan la Carrera Vieja } \\
\text { de segunda calidad, lleva en sembradura ocho celemines de } \\
\text { simiente linda con la Vereda de la referida Carrera Vieja por } \\
\text { una parte y por la otra con tierras de D. Josef Pizarro, su valor } \\
\text { es el de }\end{array}$ & 107 \\
\hline
\end{tabular}

Fuente: Archivo regional de la Comunidad de Madrid, Paracuellos, sig. 913444/1

El 11 de mayo de 1819, el Diario de Madrid publicaba que "habiendo ya manifestado todos los pueblos de esta provincia su riqueza y deseando la Junta Principal de Contribución no dilatar los medios para su reciproca igualdad ha repartido" la cantidad de 1.625 .000 pesetas entre los partidos y todos los pueblos de la provincia de Madrid, dando como resultado que cada pueblo debería pagar en concepto de impuesto directo el $13,8 \%$ de su producto neto. A continuación, este periódico insertaba en dos columnas los datos correspondientes al producto neto y la cantidad a pagar como impuesto en cada uno de los
182 pueblos, repartidos en 10 partidos, para el año 1819 en la provincia de Madrid ${ }^{14}$, más los dos reales sitios (Aranjuez y El Escorial) y los propietarios de los rebaños trashumantes. Esta nota llevaba la firma del intendente Vicente Jaudenes Nebot. ${ }^{15}$

FIGURA 5

PÁGINA DEL CUADERNO DE LA RIQUEZA DE SAN SEBASTIÁN DE LOS REYES, 1818

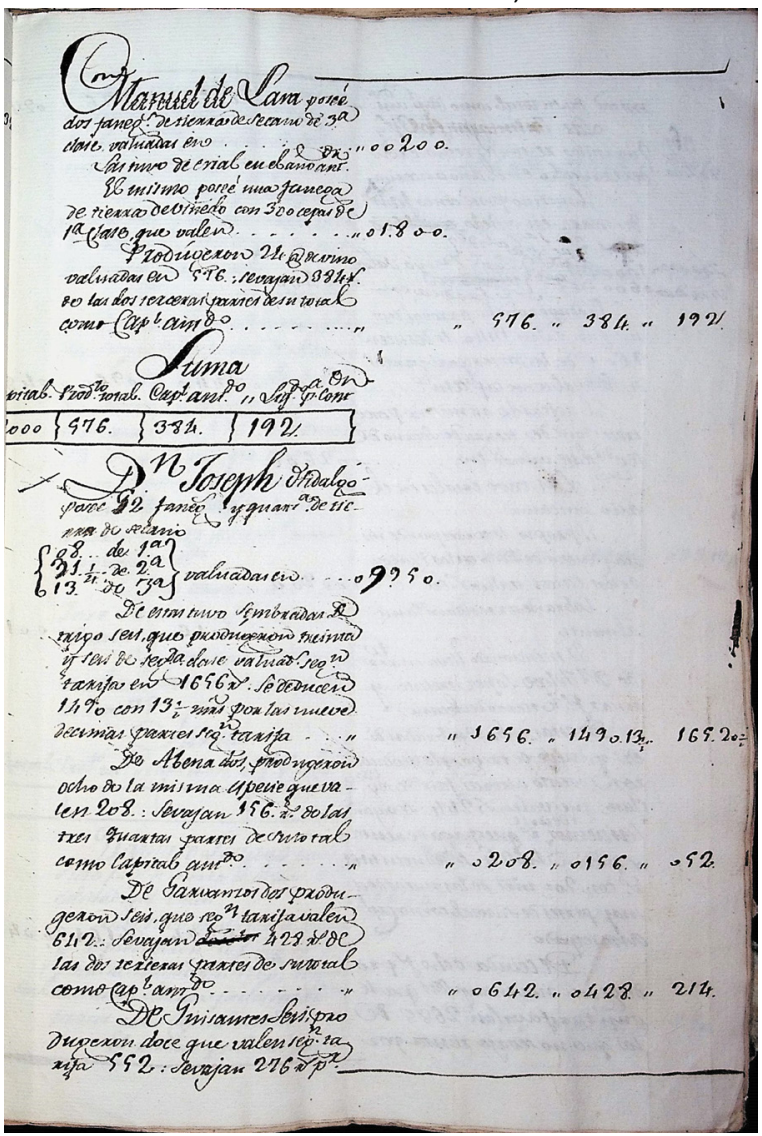

Fuente: Archivo municipal de San Sebastián de los Reyes, sig. 43/3

14 Hay que recordar que la villa de Madrid tributaba de forma indirecta mediante los Derechos de Puertas. Martínez Neira (1995: 77-89) ha estudiado cómo se suprimieron las antiguas contribuciones y su sustitución por los nuevos impuestos que pagaban todos los productos que llegaban a los fielatos de las cinco puertas reales de la ciudad.

15 El Diario de Madrid junto con la Gaceta de Madrid y el Mercurio de España constituían la prensa oficial de la época. Ver también el Diario de Madrid de 26 de abril y de 29 de agosto de 1819. Donde aparecen las tablas con la igualación de la contribución de los pueblos de la provincia de Madrid. 
TABLA 1

PRODUCTO NETO Y REPARTO DE LA CONTRIBUCIÓN ENTRE LOS PUEBLOS DE CADA PARTIDO DE LA PROVINCIA DE MADRID EN 1819

\begin{tabular}{|c|c|c|c|c|}
\hline \multirow[t]{2}{*}{ Partidos } & \multicolumn{2}{|c|}{ Producto neto } & \multicolumn{2}{|c|}{$\begin{array}{l}\text { Cantidad a repartir entre los pueblos del } \\
\text { partido para el cobro de la contribución }\end{array}$} \\
\hline & pesetas & $\%$ & pesetas & $\%$ \\
\hline Alcalá de Henares & 1.565 .834 & 13,2 & 216.116 & 13,8 \\
\hline Almonacid de Zurita & 575.884 & 4,9 & 79.483 & 13,8 \\
\hline Ciempozuelos & 1.326 .034 & 11,2 & 180.096 & 13,6 \\
\hline Chinchón & 1.680 .006 & 14,2 & 229.127 & 13,6 \\
\hline Colmenar Viejo & 922.310 & 7,8 & 90.176 & 9,8 \\
\hline Fuencarral & 1.647 .169 & 13,9 & 227.342 & 13,8 \\
\hline Getafe & 1.638 .493 & 13,8 & 226.143 & 13,8 \\
\hline Navalcarnero & 1.092 .674 & 9,2 & 150.811 & 13,8 \\
\hline Valdemorillo & 440.040 & 3,7 & 54.598 & 12,4 \\
\hline Fuente el Saz & 375.971 & 3,2 & 48.935 & 13,0 \\
\hline Reales sitios de Aranjuez y El Escorial & 529.216 & 4,4 & 73.041 & 13,8 \\
\hline Ganados trashumantes de la capital & 49.107 & 0,4 & 49.107 & \\
\hline Total & 11.842 .738 & 100 & 1.625 .000 & 13,8 \\
\hline
\end{tabular}

Fuente: Diario de Madrid, 11 de mayo de 1819.

Unos días más tarde, el martes 18 de mayo, la Crónica Científica y Literaria publicaba la misma información a doble página junto con un artículo titulado Estadística en el cual se afirmaba que en la provincia de Madrid se han conseguido ya "Ios manifiestos metódicos de su riqueza en todas las producciones líquidas, con cuyas bases se ha repartido en el actual año [1819] a proporción la cuota designada", y a continuación aseguraba que es verdad que se advierte todavía algún temor en dar todo "el valor a los rendimientos para no atraerse mayor cupo, habiendo guardado cuasi todos los pueblos una cierta rebaja como entendida, lo que hace aparecer la parte céntima de contribución mucho más alta de la realmente cabe".

En la Tabla 1 se reproduce la riqueza neta de los partidos de Madrid, así como la cantidad por la cual deberían contribuir los pueblos de cada partido aplicando el porcentaje el 13,8 \%. Aunque hay cinco partidos (Colmenar Viejo, Valdemorillo, Fuente el Saz, Ciempozuelos y Chinchón) que muestran menores porcentajes debido a la decisión Real de reducir o dejar exentos del pago de la contribución a algunos pueblos de estos partidos. ${ }^{16} \mathrm{El}$ motivo de esta rebaja o condonación temporal del pago del impuesto se explica por la

16 Colmenar Viejo (Torrelodones), Valdemorillo (Galapagar y Las Rozas), Fuente el Saz (Fuente la Higuera, Viñuelas y Venturada), Ciempozuelos (Cubas de la Sagra y Griñón) y Chinchón (Brea del Tajo y Mazuecos).
FIGURA 6

PRIMERA PAGINA DEL RESUMEN DE LA RIQUEZA DE DAGANZO DE ARRIBA, 1818

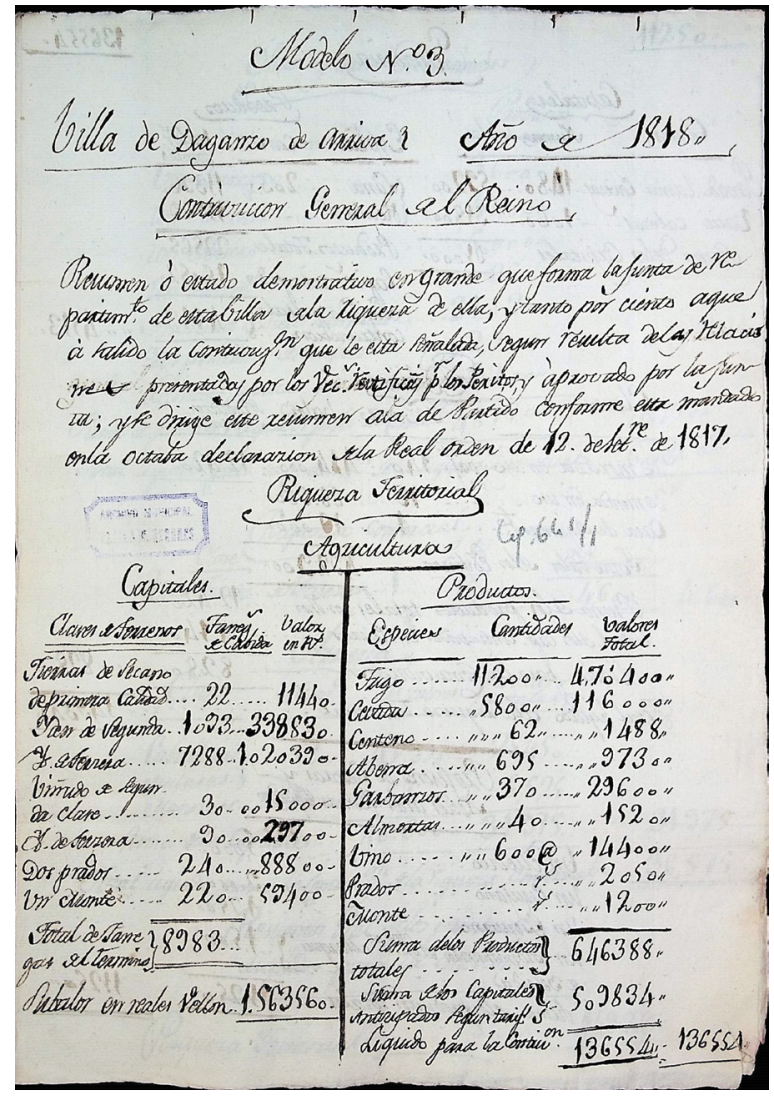

Fuente: Archivo municipal de Alcalá de Henares, sig. 641/1 
pérdida de la cosecha en estos pueblos durante 1818. Una real orden de 16 de septiembre de 1819 aclara que el Rey, con motivo de un expediente formado a la villa de San Martín de Valdeiglesias, podía declarar "rebajas o perdones de contribución a favor de los pueblos que hayan sufrido desgracias o pérdidas de sus cosechas en todo o en parte". ${ }^{17}$ No obstante, estos pueblos tienen la obligación de formar sus cuadernos generales de la riqueza con los datos correspondientes al año anterior, "para que en el siguiente se le reparta su respectiva cuota de contribución fundada en base conocida". Aunque no todos los pueblos tuvieron la misma fortuna.

El ayuntamiento de Driebes (Guadalajara) presentó un recurso al rey solicitando su "caridad y protección" ante la imposibilidad de pagar los dos tercios que debía de la contribución de 1818. A la escasez de las cosechas desde 1804/1806 había que añadir los elevados impuestos pagados a los invasores franceses, quienes, además, les habían robado 41 de las 60 mulas de labor que poseía el pueblo en 1812 y "cuyos dueños no han podido reparar esta pérdida y muchos han pasado a la clase de jornaleros con grave daño de la agricultura". En 1818 el mismo pueblo sufrió "una tormenta y tempestad de piedra" que significó la desolación y la ruina de los vecinos. Por estas causas solicitaban la real clemencia al igual que antes lo habían obtenido las cercanas villas de Mazuecos y Brea del Tajo para evitar su despoblamiento. No nos consta, sin embargo, que la obtuvieran al tener que contribuir con un total de 5.939 pesetas por los años 1817 y $1818 .{ }^{18}$

Las cifras que proporciona Canga Argüelles sobre el reparto provincial de las cuotas de la Contribución General del Reino en 1820 nos permiten conocer que Madrid aportaba a las arcas reales el 2,9\% del total lejos del 8,7 de Cataluña, del 7,9 de Galicia, del 7,6 de Sevilla o del 7,0 \% de Valencia. En cuanto a los ingresos generados por los Derechos de Puertas la ciudad de Madrid tributaba con el 25,9\% del total a mucha distancia del 11,3 de Barcelona, del 8,4 de Cádiz, del 7,5 de Valencia o del 6,9 \% de Sevilla. En total, la provincia y la villa de Madrid representaban el 7,0\% de la

17 Circular de 26 de octubre de 1819. En la real orden de 29 de octubre de 1819 se establece de forma detallada las reglas que los pueblos deben observar para solicitar que sean exonerados del pago de la contribución por haber sufrido "desgracias considerables por tempestad, incendio u otra calamidad por el general de sus vecinos". 18 La petición está fechada en Driebes el 19 de enero de 1819. Archivo municipal de Alcalá de Henares, leg. 642/1. recaudación nacional en 1820 , una cifra no muy alejada del 8,3 \% que significaban las rentas de Madrid respecto a las 22 provincias de Castilla a mediados del siglo XVIII (Canga Argüelles,1821). Ni del 7,7 \% que su riqueza imponible suponía en relación al total nacional con los datos de la estadística de 1842 (Goerlich y Mas, 2001, 71).

La Gaceta de Madrid publicaba una real orden el 24 de agosto de 1819 en la cual se reconocía que la Junta Principal de Contribución de la provincia de Madrid había efectuado ya los cálculos necesarios para el cobro equitativo de la contribución al disponer de los cuadernos generales de la riqueza de todos los pueblos de su provincia. Una real orden de 6 de octubre recuerda el atraso "en que se encuentran estas operaciones en la mayor parte de las provincias" y que, con el fin de activarlas, Fernando VII "se ha servido mandar se den las gracias en su Real nombre al Intendente y Junta principal [...] de la provincia de Madrid por el estado que ha presentado de la riqueza [en] los pueblos de la misma provincia" y ordena al Ministerio de Hacienda que remita a todas las juntas provinciales un resumen de las operaciones ya ejecutadas en Madrid para que sirven de ejemplo y "realicen la estadística de sus respectivas provincias".

En resumen, todo lo expuesto anteriormente demuestra con claridad que los responsables de realizar, al menos, los cuadernos generales de la riqueza y los resúmenes de la totalidad de los pueblos y villas de la provincia de Madrid habían concluido su trabajo en el verano de 1818, y para la primavera de 1819 muchos de los datos registrados en ellos ya habían sido verificados y rectificados por los comisarios enviados por el intendente provincial. Para entonces desconocemos si se habían completado la estadística en otras provincias, pero sí podemos afirmar que se habían terminado en muchos pueblos repartidos por todas las provincias de España, como lo demuestra la documentación localizada en los últimos años. Dos buenos ejemplos nos lo proporcionan las provincias de Ávila y Cádiz. En el Archivo Histórico Provincial de Ávila se custodian 263 apeos o libros catastros de 232 localidades abulenses más 31 pertenecientes a pueblos y villas de las provincias de Segovia, Toledo, Salamanca, Valladolid y Cáceres. ${ }^{19} \mathrm{Y}$ en los archivos gaditanos están depositados los cuadernos generales de la riqueza del $35 \%$ de los municipios que equivalen al $45 \%$ de la actual superficie de la provincia de Cádiz.

19 Archivo histórico provincial de Ávila, hacienda, legs. 310 al 350 


\section{LA LARGA MANO DEL INTENDENTE PROVINCIAL VICENTE JAUDENES}

¿Cómo se pudo finalizar esta compleja operación estadística en todo el territorio de la provincia de Madrid sujeto a la Contribución General del Reino en menos de 15 meses (de febrero de 1818 a mayo de 1819)?. A pesar de las carencias técnicas y los problemas económicos del momento, Martín de Garay tuvo que enfrentarse además a la resistencia política y económica de los grupos privilegiados y la camariIla de Fernando VII que se oponían a la aplicación de su reforma del sistema fiscal. En la documentación de archivo recientemente consultada encontramos la respuesta.

Una real orden de 18 de febrero de 1818 aclaraba que las juntas formadas en cada pueblo son las que deben realizar los apeos y los cuadernos bajo la supervisión de las juntas de partido. En esta real orden se incluye un modelo impreso que debería servir de guía para su ejecución y para homogeneizar y estandarizar la información contenida en estos cuadernos. A partir de ese momento, el intendente de Madrid y la Junta Provincial comenzaron a tomar medidas dirigidas a completar estas averiguaciones estadísticas en toda la provincia.

A través de una circular del 5 de marzo, la intendencia envía a las juntas de partido un ejemplar de esta real orden y del modelo, "porque las reglas que ellos contienen tan claras y sencillas facilitarán a V.V. las operaciones". El 29 de marzo, se reitera que estos modelos se lean "con cuidado muchas veces" para llenarse "con la mayor exactitud y pueda saberse la verdadera riqueza de los vecinos". Para ello, las juntas locales deben nombrar peritos de la "mejor opinión y más acreditada inteligencia [...] de cualquier pueblo inmediato". En las circulares de 16 y de 26 de abril, el intendente pretende estimular el celo de las juntas para concluir a tiempo la estadística ya que "es indispensable que [...] no se descuiden un momento en formar el cuaderno general de riqueza". Una comunicación del 19 de mayo dejaba claro que los trabajos no se habían concluido. La realidad era que avanzaban con mucha lentitud.

El 12 de junio de 1818, el intendente Vicente Jaudenes denuncia la "morosidad [y] la poca energía de algunas juntas de los partidos" en finalizar la estadística. Entre el 14 y el 24 de julio se reiteran en la necesidad de redoblar los trabajos para presentar los cuadernos y sus resúmenes en los próximos días. En una circular de 18 de julio se advierte de que las juntas de partido que no terminen sus trabajos serán multadas "irremisiblemente con 300 ducados", y el 28 de julio se requiere a la de Chinchón que ante los atrasos "no se pierda momento, y aprovechándose horas extraordinarias, pues en el término de diez días ha de quedar concluidos". Ese mismo día, el Ministerio de Hacienda ordena que se cumplimente la estadística en todo el territorio nacional y autoriza a los intendentes y a las juntas provinciales a que nombren comisarios entre "sujetos celosos, instruidos y bien penetrado de los elementos de la contribución general" para que hagan los apeos y los cuadernos de la riqueza, procurando conciliar "la brevedad con la veracidad de los datos".

En el caso de la provincia de Madrid, las amenazas de sanciones económicas y el problema que suponía que el intendente enviase un comisario a todos los pueblos para verificar los trabajos realizados y pagados a costa de los contribuyentes, dio como resultado que los cuadernos generales de la riqueza fueron terminados durante el verano de 1818. Entre el 23 de junio y el 19 de septiembre las juntas locales de los 15 pueblos del partido de Chinchón rubricaron los resúmenes de sus cuadernos ( 1 en junio, 2 en julio, 8 en agosto y 4 en septiembre) al tiempo que también lo hacían en el $77 \%$ de las villas y lugares localizados en Madrid. En una circular del 9 de agosto, el intendente reconoce "que muchos pueblos han presentado los cuadernos de la riqueza" pero que a medida que las autoridades van recibiendo los estadillos con los resúmenes de cada partido, observa -circular del 10 de octubre- la inexactitud de los datos de algunos pueblos. Para corregir esta situación y conocer su verdadera riqueza toma la decisión de que se proceda "inmediatamente a rectificar los trabajos que tienen remitidos" y que los comisionados "formen un nuevo estado demostrativo de estas operaciones rectificadas", como ocurrió en el partido de Chinchón, donde se modificaron de nuevo los resúmenes de todos los pueblos en tan sólo 15 días (del 26 de febrero al 13 de marzo de 1819). ${ }^{20}$

Terminados los trabajos estadísticos en Madrid, estos deberían servir de ejemplo al resto de las administraciones provinciales y locales para concluir sus indagaciones y redactar finalmente los cuadernos. A finales de agosto de 1819, el Rey agradece al intendente y la junta provincial de Madrid sus esfuerzos y

20 La villa de Carabaña había rectificado su cuaderno de la riqueza y ejecutado, de nuevo, al menos en 3 ocasiones su resumen (23 de septiembre, 26 de octubre y 3 de noviembre de 1820). Archivo regional de la Comunidad de Madrid, Carabaña, sig. 16871/1. 
ordena que se envíen a todas las juntas principales de España una copia de estas operaciones. En una circular de julio de 1818, Vicente Jaudenes ya mencionaba que "la provincia de Madrid debería ser la primera en acreditar su obediencia a las reales órdenes y servir de modelo a las demás". ${ }^{21}$

El empeño y la determinación del intendente y de los miembros que formaban parte de la junta principal de Madrid, manifestados a través de las numerosas y reiteradas normas y avisos que dirigieron a todas las juntas de partido y locales fueron la clave para explicar que en la provincia de Madrid se concluyeran las revisiones de los cuadernos de la riqueza a principios de 1819 y se pudiera realizar el reparto de la contribución general del reino como se había dictado en el Real Decreto de 30 de mayo de 1817. Primero, animando a la ejecución de la estadística y explicando sus ventajas, después, fijando plazos y multas económicas a las juntas y los pueblos que no cumplieran con sus obligaciones fijadas en las reales órdenes de 25 de noviembre de 1817 y del 18 de febrero de 1818 , y más tarde, imponiendo a las juntas de partido y locales un comisionado con la tarea de realizar y, si fuera necesario supervisar y rectificar sus trabajos estadísticos. La cercanía al poder central, la indudable presión que debió ejercer el Ministerio de Hacienda y la decidida intervención del intendente provincial reiterando "órdenes estrechas y terminantes" son los argumentos que nos tienen que ayudar a entender por qué se terminaron elaborando los cuadernos generales de la riqueza en todas las villas y pueblos de la provincia de Madrid.

\section{LA ESTADÍSTICA GENERAL DEL REINO EN LA COMUNIDAD DE MADRID, 1817-1820}

La búsqueda de esta fuente ha dado como resultado la localización de un importante corpus documental relacionado con la Estadística General del Reino en distintos archivos de la Comunidad de Madrid. Aunque sólo una parte del total de los apeos y cuadernos realizados entre 1818 y 1820 han sobrevivido y han

21 En el Diario de Madrid del 1 de noviembre de 1818 se publica una orden en la cual se insta al alcalde de Perales del Río a que active los trabajos estadísticos para que en el plazo de un mes se concluya el apeo ya que la valuación general de toda la riqueza de esta villa "está muy atrasada". Una circular del 26 de diciembre de 1818 asegura que "tenemos pendiente ahora los estados pedidos con urgencia [como] el apeo y valuación general, o sea el libro patrón". podido ser desenterrados de los fondos depositados en los archivos municipales. ${ }^{22}$

La principal dificultad para su localización reside en que los documentos originales fueron depositados en los ayuntamientos. Los archivos municipales conservan una cantidad muy importante de nuestro patrimonio documental, como afirma Cerdá "no podemos olvidar que los municipales son los archivos que atesoran mayor riqueza de fondos históricos" (Cerdá, 1997, 325), pero son también los que han recibido menor atención de la administración y sus documentos históricos los que han sufrido mayor número de agresiones poniendo en serio peligro, en muchos casos, su conservación. Su número, la dispersión geográfica, en muchas ocasiones las dificultades que plantea el acceso a su documentación y la falta de inventarios detallados o de registros digitalizados han sido en muchas ocasiones obstáculos que han dificultado enormemente el conocimiento de la ubicación de esta documentación.

Hagamos un breve recorrido por los fondos localizados en la Comunidad de Madrid.

En el Fondo de la Delegación de Hacienda de Madrid -fondo exento- del Archivo Histórico Nacional se custodian los cuadernos de Vallecas y NavalagameIla. Al final del segundo cuaderno se añade una nota en la cual se certifica que es una copia del original de 1818 , realizada por el comisionado encargado de recabar y contrastar información para el cobro de la contribución de Frutos Civiles en $1825 .{ }^{23}$ Esta nota es un indicio de que los cuadernos generales de la riqueza fueron reutilizados como base de datos para el reparto de los impuestos en la segunda restauración de Fernando VII, después del Trienio Constitucional. Una nota equivalente está asociada al cuaderno de San Sebastián de los Reyes de $1818^{24}$, y en su archivo municipal se conservan también el apeo y el cuaderno de Fuente del Fresno y las relaciones juradas de los vecinos de Alcobendas y Barajas de 1817.

Los archivos municipales de Getafe y El Escorial nos han permitido acceder a los cuadernos generales de la riqueza y sus resúmenes, así como a otros

22 La relación detallada de los fondos localizados se puede consultar en el anexo al final del trabajo.

23 Navalagamella a 26 de agosto de 1825. Archivo Histórico Nacional, delegación de hacienda de Madrid, fondo exento, leg. 1229.

24 Archivo municipal de San Sebastián de los Reyes, sig. $43 / 3$. 
de los documentos que forman parte de los cuadernos, como son los precios medios y el cálculo de los costes medios de producción de 1813 a 1817 de los partidos de Getafe y Valdemorillo para los años 1818 y 1819.

En el Archivo General de la Villa de Madrid se encuentra una abundante documentación relacionada con la administración y el cobro de la Contribución General del Reino en la provincia de Madrid y los Derechos de Puertas en la capital. También podemos consultar varios ejemplares impresos de los Modelos de la Contribución General del Reino repartidos por toda la comunidad y reimpresos en cada una de las provincias españolas para facilitar la redacción de los cuadernos generales de la riqueza.

Los archivos municipales de Alcalá de Henares y Chinchón cobijan entre sus fondos un importante conjunto de documentos generados por la Contribución General del Reino. En el archivo alcalaíno podemos examinar los resúmenes de los cuadernos de 18 de los 21 pueblos y villas que formaban el partido de Alcalá de Henares. No se han encontrado los resúmenes de Camarmilla, Belvis del Jarama ${ }^{25}$ y la villa de Alcalá de Henares, aunque sí el de su despoblado, El Encín de 1818. ${ }^{26}$ Tampoco están los apeos y sólo se puede analizar la parte del cuaderno de Camarma de Esteruelas -diciembre de 1819-, donde se describen las producciones agrícolas de 63 vecinos y 47 hacendados forasteros, entre ellos dos colegios, una iglesia magistral y un convento de monjas carmelitas. ${ }^{27}$

Por su parte, el archivo municipal de Chinchón conserva en su sección de hacienda más de 100 signaturas con documentación administrativa, fiscal y

25 El cuaderno de Belvis del Jarama fue redactado por Juan de Dios Trillo, su único arrendatario, y el perito agrimensor Francisco Izquierdo en abril de 1818. Esta pequeña localidad de 665 hectáreas era "un coto y caserío" propiedad del XIV Duque de Medinaceli.

26 El Encin es un despoblado de 152 hectáreas situado al noreste de Alcalá de Henares propiedad del Marqués de Bendaña y habitado por un solo vecino.

27 Un cuaderno más completo de esta villa -septiembre de 1818- se puede consultar en Archivo regional de la Comunidad de Madrid, así como el apeo de Paracuellos del Jarama de agosto de 1819. Un ejemplo de la información que contiene este apeo son las descripciones, más las ubicaciones, de las 31 parcelas (204 hectáreas) de los bienes de Propios junto a las 2 casas, 1 carnicería, 1 mesón y 1 barca propiedad del ayuntamiento. Ver Camarma de Esteruelas, sig. 75878 y Paracuellos del Jarama, sig. 913444/1. estadística relacionadas con la Contribución General del Reino. Además del apeo, se puede consultar el cuaderno de la villa de Chinchón de 728 páginas y firmado el 7 de agosto de 1818 por los siete peritos encargados de su elaboración, que estuvo expuesto en el ayuntamiento durante un plazo de nueve días para que "todos los vecinos y forasteros y en su nombre sus apoderados y administradores terratenientes de esta villa [conozcan] las utilidades pertenecientes a ellos para el repartimiento"28. En este archivo se pueden analizar los resúmenes de los cuadernos -modelos 3- de los 15 pueblos y villas, fechados entre junio y septiembre de 1818 , que formaban la totalidad del partido de Chinchón. Y también los nuevos resúmenes realizados por el comisionado Pablo María de Olivé, enviado por el Intendente provincial y la Junta de Partido para verificar, y en su caso, rectificar los datos expresados en los resúmenes locales. Estos fueron aprobados definitivamente entre febrero y marzo de 1819.

Los archivos municipales de Alcalá de Henares y Chinchón albergan entre sus fondos la mayor parte de la documentación producida por ambas juntas de partido para el cobro de la contribución y la ejecución de la estadística, al igual que la correspondencia enviada por el intendente provincial a estas juntas de partido y de estas a todas las juntas de los pueblos de su jurisdicción. Toda esta documentación va a permitir que se pueda reconstruir de forma detallada el proceso completo de gestación y finalización de los apeos generales y las estadísticas en los pueblos de estos dos partidos.

En el Archivo regional de la Comunidad de Madrid pueden consultarse documentos de 67 municipios madrileños (el 37,5 \% del total). Dentro de la sección de Fondos Municipales hemos localizado un importante conjunto de documentos relacionados con las relaciones juradas, los apeos y los cuadernos confeccionados en 14 villas y lugares de Madrid entre 1817 y 1820. Más en concreto, en este archivo están depositados los apeos de Bustarviejo, Paracuellos del Jarama, Valdaracete y Villaconejos, y los cuadernos

28 Algunos ejemplos de las propiedades individuales y colectivas de los residentes o foráneos descritas en este cuaderno son las del Convento de las Monjas Franciscanas con sus 16,0 hectáreas de tierras, 24 censos, 4 casas, 1 posadas, 4.100 cepas y 1.662 olivo o el Ayuntamiento de Chinchón que era propietario de 34,46 hectáreas de tierras, 71 olivos, 2 casas, 1 posada, 1 molino aceitero, 39 censos y los derechos devengados por las alcabalas. 
de Bustarviejo, Cabrera, Camarma de Esteruelas, Carabaña, Loeches, Rascafría y El Paular, San Martín de la Vega, Serranillos del Valle, Valdaracete, Valdilecha y Villamanta.

En otros archivos municipales (Algete, Alcorcón, Alcobendas, Leganés, Majadahonda, Pozuelo de Alarcón, San Fernando de Henares, Torrelodones, Guadarrama, Valdemoro y Villaviciosa de Odón) no ha sido posible hallar ningún rastro de la Estadística General del Reino. En el archivo de Rivas-Vaciamadrid la documentación del siglo XIX desapareció durante la Guerra Civil al ser este lugar frente de guerra durante la batalla del Jarama. En realidad, esta afirmación es extensible a más archivos madrileños. La Guerra Civil trajo como una de sus consecuencias la destrucción, total o parcial, de entre el 5 y el 10 $\%$ de los archivos municipales españoles situados la mayoría en pequeños núcleos de población. Madrid fue una de las provincias más afectadas por las incautaciones y las destrucciones del patrimonio documental junto con Castellón, Teruel, Huesca, Tarragona y Lérida por las acciones militares y para evitar su utilización en la represión política. En total fueron 42 los archivos afectados en la provincia de Madrid: 19 dañados totalmente y 23 de forma parcial (Cerdá, 1997, 254-268). ${ }^{29}$ A lo que habría que añadir como la escasez de papel, durante la guerra y la inmediata posguerra, fue otro desencadenante de la eliminación de documentación histórica en muchos archivos municipales para su conversión en pasta de papel y posterior reutilización.

Tampoco podemos descartar la pérdida de una parte de la estadística de Martín de Garay en las destrucciones sufridas en dos importantes archivos madrileños al comienzo de la Guerra Civil. En 1936, la Junta de Defensa de Madrid escogió los depósitos del Archivo Central del Ministerio de Hacienda en la

29 Los destruidos totalmente fueron: Alcorcón, Aravaca, Colmenar Viejo, Guadalix de la Sierra, Hortaleza, Móstoles, Navas del Rey, Paredes de Buitrago, Pinto, Pozuelo de Alarcón, Rozas de Puerto Real, San Lorenzo de El Escorial, San Martín de Valdeiglesias, Titulcia, Villaconejos, Villanueva de la Cañada, Villanueva del Pardillo, Villaverde y Villaviciosa de Odón. Y los damnificados parcialmente: Arroyomolinos, Buitrago de Lozoya, Casarrubuelos, Chozas de la Sierra, Colmenarejo, El Escorial, Horcajo de la Sierra, La Hirula, Lozoya, Miraflores de la Sierra, Navalcarnero, Navarredonda, Pelayos de la Presa, Pinilla del Valle, Rascafría, Rivas del Jarama, Robledo de Chavela, Santa María de la Alameda, Tielmes, Torrejón de la Calzada, Torrelaguna, Vicálvaro y Zarzalejo.
Casa Central de Aduanas para ser utilizados como bunker y refugio antiaéreo. Los legajos fueron vendidos como papel viejo o abandonados en los patios lo que supuso la pérdida de gran parte del fondo documental del siglo XIX. No debe sorprender que en la guía de los fondos históricos supervivientes de este archivo publicada en 1962 no figure ninguna referencia a la documentación de la Contribución General del Reino (Matilla y Martínez, 1962). En agosto de ese mismo año, el Archivo General Central de Alcalá de Henares, situado en el antiguo palacio de los arzobispos de Toledo, sufrió un incendio en el que desapareció la totalidad de los documentos que albergaba desde su creación en 1858. Entre ellos, los relacionados con la fiscalidad, la organización administrativa y la normativa de la Real Hacienda anterior a la reforma de 1845 . Para Matilla la mayor parte de la documentación económica del XIX, especialmente la de su primera mitad, "se convirtió en humos y cenizas un aciago día en Alcalá de Henares. Todos los Ministerios habían remesado allá ingente cantidad de papeles" (Matilla, 1957).

En resumen, se ha conseguido, hasta el momento, localizar un total de 14 relaciones juradas, 7 apeos, 20 cuadernos y 41 resúmenes relacionadas con la Estadística General del Reino correspondientes a otras tantas villas y pueblos situados principalmente al sureste de la Comunidad de Madrid y elaborados entre 1817 y 1820 (Tabla 2). Estos cuadernos generales de la riqueza representan al $11,2 \%$ de los municipios madrileños y los resúmenes locales al 22,9 \% lo que convierte a esta documentación nacida de la reforma de la hacienda de Martín de Garay, en una fuente histórica y geográfica de primer orden para estudiar tanto los componentes sociales y económicos como las características del territorio y del paisaje de Madrid a principios del siglo XIX.

Un sondeo preliminar nos ha permitido comparar los datos de la producción del trigo, la cebada, el vino y el aceite de los resúmenes de 1819 en los pueblos de los partidos de Chinchón y Alcalá de Henares, y el recuento efectuado por Antonio Regás entre 1824 y 1825 , nos muestra que hay notables diferencias a favor de la mayor solvencia de la información contenida en los cuadernos generales de la riqueza. Las cantidades declaradas en esta fuente fiscal son de un 37 $\%$ superiores para el trigo y la cebada, un $29 \%$ para el vino y un $16 \%$ para el aceite (Regás, 1835, 51-57). De igual forma, los datos fiscales sobre la riqueza en el partido de Chinchón en 1813 son inferiores a los registrados en la estadística de 1819: un 8 \% en el número de cepas, un $14,0 \%$ en los olivos, un $15,4 \%$ en el 
TABLA 2

LA ESTADÍSTICA GENERAL DEL REINO LOCALIZADA EN LA COMUNIDAD DE MADRID

\begin{tabular}{|c|c|c|c|c|}
\hline \multirow[b]{2}{*}{$\begin{array}{c}\text { Villas, pueblos, lugares } \\
\text { y despoblados }\end{array}$} & \multicolumn{4}{|c|}{ Tipos documentales } \\
\hline & $\begin{array}{c}\text { Relaciones juradas } \\
\text { de los vecinos, 1817-1820 }\end{array}$ & Apeos, $1818-1820$ & $\begin{array}{c}\text { Cuadernos } \\
\text { de la riqueza, } \\
1818-1820\end{array}$ & $\begin{array}{l}\text { Resúmenes de } \\
\text { los cuadernos, } \\
1818-1820\end{array}$ \\
\hline Ajalvir & 1818 & & & 1818 \\
\hline Alcobendas & 1817 & & & \\
\hline Algete & & & & 1818 \\
\hline Arganda del Rey & & & & $1818-1819$ \\
\hline Barajas & 1817 & 1819 & & \\
\hline Bayona / Titulcia & & & & $1818-1819$ \\
\hline Belmonte de Tajo & & & & $1818-1819$ \\
\hline Belvis del Jarama & & & 1818 & \\
\hline Brea del Tajo & & & & $1818-1819$ \\
\hline Bujes & & & & 1818 \\
\hline Bustarviejo & & 1818 & $1819-1820$ & \\
\hline Cabrera & & & 1818 & \\
\hline Camarma de Esteruelas & & & 1819 & 1818 \\
\hline Camarma de Suso & & & & 1818 \\
\hline Camarma del Caño & & & & $1818-1820$ \\
\hline Campo Real & & & & $1818-1819$ \\
\hline Carabaña & & & 1820 & $1818-1819-1820$ \\
\hline Casarrubuelos & 1818 & & & \\
\hline Chinchón & $1817-1818$ & 1819 & 1818 & $1818-1819$ \\
\hline Cobeña & & & & 1818 \\
\hline Daganzo de Abajo & & & & 1818 \\
\hline Daganzo de Arriba & & & & 1818 \\
\hline Driebes (Guadalajara) & & & & $1818-1819$ \\
\hline Encin, El & & & 1818 & 1818 \\
\hline Escorial, El & & & 1820 & 1820 \\
\hline Fresno de Torote & & & & 1818 \\
\hline Fuente el Fresno & 1817 & 1819 & 1819 & 1819 \\
\hline Fuentidueña de Tajo & 1818 & & & \\
\hline Getafe & & & 1818 & 1818 \\
\hline Hueros, Los & & & & 1818 \\
\hline Loeches & & & $1819-1820$ & $1818-1820$ \\
\hline Mazuecos (Guadalajara) & & & & $1818-1819$ \\
\hline Meco & & & & $1818-1820$ \\
\hline Mejorada del Campo & & & & 1818 \\
\hline Méndrida (Toledo) & 1818 & & & \\
\hline Morata de Tajuña & & & & $1818-1819$ \\
\hline Navalagamella & & & 1818 & \\
\hline Navalcarnero & 1818 & & & \\
\hline
\end{tabular}




\begin{tabular}{|c|c|c|c|c|}
\hline \multirow[b]{2}{*}{$\begin{array}{c}\text { Villas, pueblos, lugares } \\
\text { y despoblados }\end{array}$} & \multicolumn{4}{|c|}{ Tipos documentales } \\
\hline & $\begin{array}{l}\text { Relaciones juradas } \\
\text { de los vecinos, 1817-1820 }\end{array}$ & Apeos, $1818-1820$ & $\begin{array}{c}\text { Cuadernos } \\
\text { de la riqueza, } \\
1818-1820 \\
\end{array}$ & $\begin{array}{l}\text { Resúmenes de } \\
\text { los cuadernos, } \\
1818-1820 \\
\end{array}$ \\
\hline Orusco de Tajuña & & & & $1818-1819$ \\
\hline Paracuelllos del Jarama & 1819 & 1819 & & 1818 \\
\hline Perales de Tajuña & & & & $1818-1819$ \\
\hline Rascafría y El Paular & & & $1818-1820$ & \\
\hline San Martín de la Vega & & & 1819 & \\
\hline San Sebastián de los Reyes & 1817 & & 1818 & 1818 \\
\hline Serranillos del Valle & & & 1818 & $1818-1820$ \\
\hline Tielmes & & & & $1818-1819$ \\
\hline Torrejón de Ardoz & & & & 1818 \\
\hline Torres de la Alameda & & & & 1818 \\
\hline Valdaracete & 1819 & $1819-1820$ & 1820 & \\
\hline Valdelagua & & & & $1818-1819$ \\
\hline Valdilecha & & & 1818 & $1818-1819$ \\
\hline Vallecas & & & $1818-1820$ & \\
\hline Valmojado (Toledo) & 1818 & & & \\
\hline Valverde de Alcalá & & & & $1818-1820$ \\
\hline Velilla de San Antonio & & & & 1818 \\
\hline Villaconejos & & 1820 & & \\
\hline Villamanta & $1817-1818$ & & 1818 & $1818-1820$ \\
\hline Total & 14 & 7 & 20 & 41 \\
\hline $\begin{array}{l}\% \text { sobre el total } \\
\text { de municipios }\end{array}$ & 7,8 & 3,9 & 11,2 & 22,9 \\
\hline
\end{tabular}

Fuente: elaboración propia

cómputo de las casas y la cifra aumenta hasta el 51,5 $\%$ si comparamos las ovejas y las cabras. ${ }^{30}$

A corto plazo los apeos y los cuadernos generales de la riqueza sirvieron de base de datos para hacer comparaciones con otros datos fiscales posteriores.

Así se hizo, por ejemplo, en algunas localidades madrileñas se emplearon las cifras de 1818-1819 para contrastarlas con los resultados obtenidos para el cobro de la contribución de los Frutos Civiles de $1825 .{ }^{31} \mathrm{El}$ gobierno constitucional del Trienio Liberal no desechó las ideas de Garay, sino que se inspiró en ellas para la nueva reforma de la Hacienda Pública y los nuevos cuadernos generales de la contribución territorial a pesar

30 Archivo municipal de Chinchón, sig. 8068.

31 Archivo Histórico Nacional, delegación de hacienda de Madrid, fondo exento, leg. 1229 y Archivo municipal de San Sebastián de los Reyes, sig. 43/3. de las críticas de Canga Argüelles (Toledano, 1860, 425426). Manuel Cortina, ministro de la Gobernación en el gabinete de Espartero, propone de nuevo la realización de una estadística sobre la riqueza como piedra angular de la reforma fiscal y para la mejora de las condiciones materiales del país. En el decreto de 7 de febrero de 1841 no se menciona el trabajo de Martín de Garay pero su influencia es evidente en el texto de la ley sobre todo en lo relativo al cálculo de la materia imponible -o riqueza neta- y de la renta/utilidad líquida o riqueza líquida como base para el cobro de los impuestos al igual que el modelo desarrollado en los cuadernos generales de la riqueza en $1818 .^{32}$

32 Gaceta de Madrid de 9 de febrero de 1841 y Boletín Oficial de Madrid de 20 y 23 de febrero de 1841. Un ejemplo de los resultados de esta estadística referidos a los pueblos y el partido de Chinchón en abril de 1841 se puede consultar en el Archivo municipal de Chinchón, sig. 8739. 
A medio plazo, también mostraron su valor jurídico como registros de la propiedad inmobiliaria (tierras y casas), al ser empleados como documentos oficiales para obtener certificados de propiedad con validez legal, en litigios públicos ante la administración o privados entre individuos para determinar los derechos de propiedad sobre bienes inmuebles.

María Faustina Palomares, administradora de las tierras que María de los Dolores Chaves Contreras, $\mathrm{V}$ marquesa de Bermudo y IV condesa viuda de Superunda, poseía en el pueblo abulense de Cabezas del Pozo, solicitó, en agosto de 1860, un certificado que avalase que estas tierras eran propiedad de la marquesa. El encargado de complementar esta solicitud fue Bernardino Fernández Blanco, abogado y responsable del Archivo General de Hacienda de Ávila. En el certificado reproducen una a una de forma textual, las 34 parcelas de secano propiedad de la marquesa según constaba en el "apeo y valuación general de capitales del pueblo de Cabezas del Pozo del partido de Arévalo de esta provincia verificado en [1818] para el establecimiento de la contribución directa" en virtud de lo dispuesto en la real orden de 18 de febrero de 1818 que "se custodia en el archivo general de hacienda pública de esta provincia que corre a mi cargo". ${ }^{33}$ Este documento es sólo un ejemplo de cómo estos apeos se convirtieron en un registro oficial de la propiedad de los bienes inmuebles con anterioridad a la creación del Registro de la Propiedad en España, establecido a partir de la Ley Hipotecaria de 1861 y que entró en vigor en 1863.

\section{CONCLUSIONES}

Juan de Pipaón, protagonista de la novela La segunda casaca de Pérez Galdos, aseguraba que todos en su tiempo estaban en contra de Martín de Garay y por ello fue cesado de su cargo de Ministro de Hacienda en septiembre de 1818. En la prensa de la época se escribía que apenas había dado a luz el decreto de 30 de mayo de 1817 estableciendo la contribución general "cuando los apóstoles del antiguo sistema, puestos de acuerdo con las clases privilegiadas, [...] empezaron a contrariar el régimen naciente, y valiéndose de todas las supercherías y vilezas [...]

33 Archivo Histórico de la Nobleza, Toreno, C.42/D.17. El apeo y el cuaderno de Cabezas del Pozo de 1818 están depositados en el Archivo histórico provincial de Ávila, hacienda, leg. 315. trataron de minar y destruir el edificio que empezaba a levantarse". ${ }^{34}$ Además no debemos olvidarnos de la desconfianza que había provocado el nuevo catastro y su estadística entre los campesinos al considerarla como un mecanismo para agravar sus intereses "bajo cuyo principio falso han manifestado igualmente su oposición y han arrinconado hace tiempo tan interesante obra". ${ }^{35}$ La reforma de este ministro liberal fracasó, pero los esfuerzos de Martín de Garay continuados por José Imaz y Antonio González nos han dejado como herencia, 200 años después, un importante patrimonio documental que ha vencido el tiempo y nos han legado una fuente geohistórica -un catastro textual y una estadística- capaz de describir el territorio, la economía y la sociedad española recién acabada la Guerra de la Independencia y antes de los profundos cambios introducidos a partir de las décadas de los años cuarenta y cincuenta del siglo XIX, a pesar de las posibles sombras que se pueden proyectar sobre esta fuente de naturaleza fiscal.

A diferencia de Madrid y algunas otras provincias donde se llegó a completar la estadística, o una parte considerable de la misma, en otras provincias es muy probable que sólo se llegara a concluir en algunos pueblos como hasta el momento se ha podido acreditar localizando esta documentación en distintos archivos municipales y provinciales. En el caso de Madrid, la presión del poder central y la decidida voluntad del intendente provincial quien empleando todas las herramientas legales y coactivas a su disposición pudieron conseguir que las juntas de los partidos y las juntas locales completasen los cuadernos generales de la riqueza de todas las villas y pueblos durante el verano de 1818 para proceder al reparto de la contribución general del reino. La estadística elaborada en Madrid debía servir de ejemplo al resto de las provincias y de cómo las normas dictadas desde el Ministerio de Hacienda en 1817 podían dar como resultado la recopilación de la información geohistórica más importante realizada a principios del siglo XIX y que, en muchos casos, todavía está esperando a ser rescatada de nuestros archivos.

34 Diario constitucional de Barcelona, 18 de marzo de 1820, p. 23.

35 Muchos fueron los que se declararon contra la formación de la estadística y por "la cuenta que les tenía han coadyuvado a que los sencillos labradores cayesen en el insinuado error de que estadística es lo mismo que contribución gravosa para que la mirasen con odio" Diario constitucional, político y mercantil de Barcelona, 11 de junio de 1820, pp. 1 y 2. 


\section{REFERENCIAS BIBLIOGRÁFICAS}

(1789). España dividida en provincias e intendencias, y subdividida en partidos, corregimientos, alcaldías mayores, gobiernos políticos y militares, así realengos como de ordenas, abadengo y señorío. 2 vols. Madrid.

Alonso Garcés, N. (2009). Biografía de un liberal aragonés. Martín de Garay (1771-1822). Zaragoza: Institución Fernando el Católico.

Bringas Gutiérrez, M.A. (1994). “Los cuadernos generales de la riqueza (1818-1820): la localización de una fuente histórica en España". Noticiario de Historia Agraria, año IV, núm. 7, pp. 155-179. Murcia.

Bringas Gutiérrez, M.A. (2003). "Un catastro poco conocido: el apeo y valuación general de Martín de Garay, 1818-1820". CT Catastro, núm. 47, pp. 143157. Madrid.

Bringas Gutiérrez, M.A. (2008). "Estructura documental de los cuadernos generales de la riqueza de Martín de Garay, 1818-1820". CT Catastro, núm. 64, pp. 79-109. Madrid.

Bringas, M.A., Mazo, I. y Mercapide, G. (2017). "Valoración catastral de la propiedad urbana en una ciudad española. El apeo de casas y edificios de Logroño, 1818-1820", CT Catastro, núm. 91, pp. 83-114. Madrid.

Bringas, M.A., Mazo, I., Mercapide, G., García, L., Vallina, A. y Aguilar, A. I. (2019). “Logroño, 1818-1820: población y estructura urbana a partir del análisis de una fuente catastral", XII Congreso de la Asociación de Demografía Histórica. Oporto, 4 al 7 de septiembre de 2019.

Burgueño, J. (1997). “La reforma de la división provincial en la meseta meridional (1800-1850)". Estudios Geográficos, núm. 228, pp. 355-376. Madrid.

Canga-Argüelles, J. (1821). Nota de las cuotas de la contribución general y de las equivalentes a los derechos suprimidos de puertas impuestas a cada provincia por las Cortes ordinarias en decreto de 6 de noviembre de 1820. Repartimiento de la contribución general hecha a todos los pueblos de la península. Madrid.

Camarero Bullón, C. (2001). Madrid y su provincia en el Catastro de Ensenada. 2 vols. Madrid. Ediciones del Umbral.

Cerdá Díaz, J. (1997). Los archivos municipales en la España contemporánea. Gijón: Trea.
Dalmau, F. (1820). Ensayos de estadística, practicados en la provincia de Granada. Madrid.

García-Pulido, L.J. (2016). “Cinco siglos de Catastros, Apeos, Amillaramientos y Cartografía Parcelaria en el término municipal de Granada". CT Catastro, núm. 88, pp. 23-71. Madrid.

Goerlich Gísbert, F. J. y Mas Ivars, M. (2001). La evolución económica de las provincias españolas (19551998). Capitalización y crecimiento. Bilbao: Fundación BBV.

Hernández Andreu, J. (1972). “Evolución histórica de la contribución directa en España desde 1700 a 1814". Revista de economía política, núm.61, pp. 3190. Madrid.

Hernández Andreu, J. (2008). Orígenes de la fiscalidad contemporánea en España: la reforma de Garay (1817-1818). Madrid: Delta Publicaciones.

López Castellano, F. (1992). La contribución directa de 1813: un intento de reforma del sistema tributario del Antiguo Régimen. Tesis doctoral. Granada: Universidad de Granada.

Madoz, P. (1845/50). Diccionario geográfico-estadístico-descriptivo de España y sus posesiones de ultramar. Tomo X. Madrid.

Martínez Neira, M. (1995). Revolución y fiscalidad municipal: la hacienda de la Villa de Madrid en el reinado de Fernando VII. Madrid: Instituto de Estudios Madrileños CSIC.

Matilla Tascón, A. (1957) "La documentación económica de los archivos españoles". Boletín de la Dirección General de Archivos y Bibliotecas, núm. 44, pp. 25-26. Madrid.

Matilla Tascón, A. y Martínez Aparicio, M. (1962). Guía de los fondos históricos del Archivo Central del Ministerio de Hacienda. Madrid: Instituto de Estudios Fiscales.

Miñano Bedoya, S. (1826/29). Diccionario geográfico-estadístico de España y Portugal, tomo V. Barcelona.

Moreau de Jonnès, A. (1835). Estadística de España. Territorio, población, agricultura, industria, comercio, navegación, colonias y rentas. Barcelona.

Regás Bedoya, A. (1835). Estadística de la provincia de Madrid. Madrid.

Toledano, E. (1860). Curso de instituciones de hacienda pública de España, tomo I. Madrid. 
ANEXO

LA ESTADÍSTICA GENERAL DEL REINO EN LOS ARCHIVOS DE LA COMUNIDAD DE MADRID, 1817-1820

\begin{tabular}{|c|c|c|c|}
\hline \multicolumn{4}{|c|}{ Archivo Histórico Nacional } \\
\hline Pueblo o villas & Tipo de documentación & Fecha & Sección/legajo \\
\hline \multirow[b]{2}{*}{ Vallecas } & Cuaderno general de la riqueza & $--/--/ 1818$ & \multirow{2}{*}{$\begin{array}{l}\text { F. D. Hacienda } \\
\text { de Madrid. } \\
\text { F.E. siglo XIX, } \\
\text { leg. } 536\end{array}$} \\
\hline & Cuaderno general de la riqueza & $--/--/ 1820$ & \\
\hline Navalagamella & Cuaderno general de la riqueza & $--/--/ 1818$ & \multirow{2}{*}{$\begin{array}{l}\text { F. D. Hacienda } \\
\text { de Madrid. F. } \\
\text { E. siglo XIX, } \\
\text { leg. } 1229\end{array}$} \\
\hline Valdemorillo & Repartimiento de la contribución general del reino & $04 / 10 / 1817$ & \\
\hline \multicolumn{4}{|c|}{ Archivo Municipal de El Escorial } \\
\hline $\begin{array}{l}\text { Partido de } \\
\text { Valdemorillo }\end{array}$ & Modelo 1.Tarifa de los precios medios & $--/--/ 1819$ & \multirow{3}{*}{ sig. 3738-1 } \\
\hline \multirow{2}{*}{ Escorial, El } & Cuaderno general de la riqueza & \multirow{2}{*}{$--/--/ 1820$} & \\
\hline & Modelo 3. Resumen del cuaderno & & \\
\hline \multicolumn{4}{|c|}{ Archivo Municipal de Getafe } \\
\hline \multirow{3}{*}{ Getafe } & Relaciones juradas de los bienes de los vecinos & $1817-1818$ & \multirow{6}{*}{ libro 54} \\
\hline & Repartimientos de la contribución general del reino & $1817-1818$ & \\
\hline & Circulares de la intendencia de Madrid & $1818-1819$ & \\
\hline \multirow{2}{*}{$\begin{array}{l}\text { Partido } \\
\text { de Getafe }\end{array}$} & Modelo 1. Tarifa de los precios medios & $07 / 06 / 1818$ & \\
\hline & Modelo 2. Tarifa de las partes alícuotas & $03 / 04 / 1818$ & \\
\hline \multirow{4}{*}{ Getafe } & Modelo 3. Resumen del cuaderno & $--/--/ 1818$ & \\
\hline & Cuaderno general de la riqueza & $--/--/ 1818$ & \multirow{6}{*}{ libro 554} \\
\hline & Modelo 3. Resumen del cuaderno & $--/--/ 1818$ & \\
\hline & Repartimientos de la contribución general del reino & 1819 & \\
\hline \multirow{3}{*}{$\begin{array}{c}\text { Partido } \\
\text { de Getafe }\end{array}$} & Actas de la junta de repartimiento y estadística & $1818-1819$ & \\
\hline & Modelo 1. Tarifa de los precios medios & $07 / 06 / 1818$ & \\
\hline & Modelo 2. Tarifa de las partes alícuotas & $03 / 04 / 1818$ & \\
\hline \multicolumn{4}{|c|}{ Archivo Municipal de San Sebastián de los Reyes } \\
\hline \multirow{4}{*}{$\begin{array}{l}\text { San Sebastián } \\
\text { de los Reyes }\end{array}$} & Cuaderno general de la riqueza. Agricultura y edificios & $--/--/ 1818$ & sig. $43 / 3 \mathrm{~A}$ \\
\hline & $\begin{array}{l}\text { Relaciones juradas de los bienes de los vecinos. Aprobadas y } \\
\text { rectificadas }\end{array}$ & $1817 / 1818$ & sig. $48 / 1$ \\
\hline & Cuaderno general de la riqueza. Ganadería y riqueza industrial & \multirow{2}{*}{$--/--/ 1818$} & \multirow{2}{*}{ sig. $49 / 1$} \\
\hline & Modelo 3. Resumen del cuaderno & & \\
\hline Barajas & Relaciones juradas de los bienes de los vecinos & $--/--/ 1817$ & \multirow{2}{*}{ sig. $49 / 2$} \\
\hline Alcobendas & Relaciones juradas de los bienes de los vecinos & $1817 / 1818$ & \\
\hline $\begin{array}{l}\text { San Sebastián } \\
\text { de los Reyes }\end{array}$ & Actas de la junta de contribución de San Sebastián de los Reyes & $1817 / 1819$ & sig. $50 / 2$ \\
\hline
\end{tabular}




\begin{tabular}{|c|c|c|c|}
\hline \multirow{4}{*}{$\begin{array}{l}\text { Partido de } \\
\text { Fuente el Fresno }\end{array}$} & Modelo 1. Tarifa de los precios medios & \multirow{2}{*}{ 04/08/1818 } & \multirow{2}{*}{ sig. $61 / 2$} \\
\hline & Modelo 2. Tarifa de las partes alícuotas & & \\
\hline & Modelo 1. Tarifa de los precios medios & \multirow{2}{*}{$28 / 02 / 1818$} & \multirow{7}{*}{ sig. 62} \\
\hline & Modelo 2. Tarifa de las partes alícuotas & & \\
\hline \multirow{5}{*}{ Fuente el Fresno } & Cuaderno general de la riqueza & 19/07/1818 & \\
\hline & Modelo 3. Resumen del cuaderno & $30 / 07 / 1818$ & \\
\hline & Modelo 3. Resumen del cuaderno. Rectificado & $--/--/ 1819$ & \\
\hline & Apeo y valuación general & $27 / 11 / 1818$ & \\
\hline & Cuaderno general de la riqueza & 25/04/1819 & \\
\hline \multirow{2}{*}{$\begin{array}{l}\text { Partido de } \\
\text { Fuencarral }\end{array}$} & Modelo 1. Tarifa de los precios medios & $--/--/ 1818$ & \multirow{2}{*}{ sig. $62 / 7$} \\
\hline & Modelo 2. Tarifa de las partes alícuotas & $--/--/ 1818$ & \\
\hline \multicolumn{4}{|c|}{ Archivo General de la Villa de Madrid } \\
\hline \multirow{3}{*}{$\begin{array}{l}\text { Provincia y partido } \\
\text { de Madrid }\end{array}$} & $\begin{array}{l}\text { Documentos de la Intendencia de Madrid y de la Junta de } \\
\text { repartimiento y estadística del partido de Madrid }\end{array}$ & $1817-1818$ & \multirow{4}{*}{$\begin{array}{c}\text { Secretaria } \\
\text { secc.1, } \\
\text { leg. } 494 / 18 \\
\\
\text { Secretaria } \\
\text { secc. } 2, \\
\text { leg. } 359 / 15 \\
\\
\text { Secretaria } \\
\text { secc. 3, } \\
\text { legs. } 290 / 97 \\
291 / 30-43- \\
49-97\end{array}$} \\
\hline & $\begin{array}{l}\text { Diligencias de la Intendencia de Madrid a los pueblos de la provincia } \\
\text { para que formen sus respectivas juntas }\end{array}$ & $--/--/ 1818$ & \\
\hline & Modelos de la contribución general del reino & $--/--/ 1818$ & \\
\hline Barajas & Libro de apeos, deslindes y amojonamientos del término municipal & $1817-1819$ & \\
\hline Canillejas & Cuaderno y libro cobratorio para del repartimiento & $26 / 10 / 1820$ & $\begin{array}{l}\text { AVM SEC-70- } \\
127-19\end{array}$ \\
\hline \multicolumn{4}{|c|}{ Archivo Municipal de Arganda del Rey } \\
\hline $\begin{array}{l}\text { Arganda } \\
\text { del Rey }\end{array}$ & $\begin{array}{l}\text { Comunicación del jefe político de la provincia de Madrid de las reales } \\
\text { ordenes de Fernando VII por la que se encarga a los ayuntamientos y } \\
\text { diputaciones el reparto de la contribución y la realización del catastro }\end{array}$ & $19 / 04 / 1820$ & $\begin{array}{l}\text { ES } 28014 \\
\text { AMAR } \\
010400050011\end{array}$ \\
\hline \multicolumn{4}{|c|}{ Archivo Municipal de Los Molinos } \\
\hline Molinos, Los & Repartimientos de la contribución general del reino & $1817 / 1818$ & sig. $421310 / 1$ \\
\hline \multicolumn{4}{|c|}{ Archivo Municipal de Alcalá de Henares } \\
\hline \multirow{3}{*}{$\begin{array}{l}\text { Partido de Alcalá } \\
\text { de Henares }\end{array}$} & \multirow{3}{*}{$\begin{array}{l}\text { Correspondencia entre la Intendencia de Madrid y la Junta de } \\
\text { Partido de Alcalá de Henares }\end{array}$} & $--/--/ 1818$ & leg. $79 / 24$ \\
\hline & & $--/--/ 1819$ & leg. $79 / 30$ \\
\hline & & $--/--/ 1820$ & leg. 79/39 \\
\hline Ajalvir & Relaciones juradas de los bienes de los vecinos & $--/--/ 1818$ & leg. 609/1 \\
\hline \multirow{8}{*}{$\begin{array}{l}\text { Partido de Alcalá } \\
\text { de Henares }\end{array}$} & Repartimiento provisional de la contribución & \multirow{3}{*}{$--/--/ 1817$} & \multirow{8}{*}{ leg. 640/1 } \\
\hline & $\begin{array}{l}\text { Acuerdos del ayuntamiento de Alcalá de Henares para el } \\
\text { establecimiento del sistema general de hacienda }\end{array}$ & & \\
\hline & Actas de la Junta de Contribución de Alcalá de Henares & & \\
\hline & Cuaderno de órdenes comunicadas a la Junta de Alcalá de Henares & $30 / 03 / 1818$ & \\
\hline & Modelo 1. Tarifa de los precios medios & $30 / 03 / 1818$ & \\
\hline & Modelo 2. Tarifa de las partes alícuotas & $--/--/ 1818$ & \\
\hline & Modelos para contribución general del reino & $--/--/ 1817$ & \\
\hline & Repartimiento de la contribución general del reino & $--/--/ 1817$ & \\
\hline
\end{tabular}




\begin{tabular}{|c|c|c|c|}
\hline Torrejón Ardoz & Modelo 3. Resumen del pueblo & $29 / 07 / 1818$ & \multirow{29}{*}{ leg. $641 / 1$} \\
\hline Valverde Alcalá & Modelo 3. Resumen del pueblo & $28 / 07 / 1818$ & \\
\hline Fresno de Torote & Modelo 3. Resumen del pueblo & $18 / 06 / 1818$ & \\
\hline Hueros, Los & Modelo 3. Resumen del pueblo & $30 / 04 / 1818$ & \\
\hline Velilla San Antonio & Modelo 3. Resumen del pueblo & $29 / 06 / 1818$ & \\
\hline \multirow{2}{*}{$\begin{array}{l}\text { Camarma Suso } \\
\text { (despoblado de } \\
\text { Camarma Caño) }\end{array}$} & Modelo 3. Resumen del pueblo & $03 / 09 / 1818$ & \\
\hline & Modelo 3. Resumen del pueblo & $25 / 01 / 1818$ & \\
\hline \multirow{2}{*}{ Camarma de Caño } & Modelo 3. Resumen del pueblo & $25 / 01 / 1820$ & \\
\hline & Modelo 3. Resumen del pueblo & $01 / 08 / 1818$ & \\
\hline $\begin{array}{l}\text { Camarma de } \\
\text { Esteruelas }\end{array}$ & Modelo 3. Resumen del pueblo & $03 / 09 / 1818$ & \\
\hline Daganzo Arriba & Modelo 3. Resumen del pueblo & $13 / 06 / 1818$ & \\
\hline Daganzo Abajo & Modelo 3. Resumen del pueblo & $10 / 07 / 1818$ & \\
\hline Cobeña & Modelo 3. Resumen del pueblo & $21 / 08 / 1818$ & \\
\hline Algete & Modelo 3. Resumen del pueblo & $06 / 05 / 1818$ & \\
\hline \multirow{3}{*}{ Encin, El } & Cuaderno general de la riqueza & $26 / 08 / 1818$ & \\
\hline & Modelo 3. Resumen del pueblo & & \\
\hline & Cuaderno general de la riqueza & $25 / 08 / 1818$ & \\
\hline Ajalvir & Modelo 3. Resumen del pueblo & $28 / 05 / 1818$ & \\
\hline Buges & Modelo 3. Resumen del pueblo & $03 / 08 / 1818$ & \\
\hline Meco & Modelo 3. Resumen del pueblo & $07 / 08 / 1818$ & \\
\hline ivieco & Modelo 3. Resumen del pueblo & $--/--/ 1818$ & \\
\hline Belvis Jarama & Cuaderno general de la riqueza & $30 / 04 / 1818$ & \\
\hline $\begin{array}{l}\text { Paracuellos } \\
\text { del Jarama }\end{array}$ & Modelo 3. Resumen del pueblo & $31 / 05 / 1818$ & \\
\hline Mejorada Campo & Modelo 3. Resumen del pueblo & $06 / 08 / 1818$ & \\
\hline Torres Alameda & Modelo 3. Resumen del pueblo & $01 / 09 / 1818$ & \\
\hline \multirow{9}{*}{$\begin{array}{l}\text { Partido de Alcalá } \\
\text { de Henares }\end{array}$} & Correspondencia del intendente Vicente Jaudenes & $1818 / 1819$ & \\
\hline & Modelo 3 impreso sin rellenar & sin fecha & \\
\hline & Correspondencia de la Junta de Partido de Alcalá de Henares & $1818 / 1819$ & \\
\hline & Actas de la Junta de Contribución de Alcalá de Henares & 1818 & \\
\hline & $\begin{array}{c}\text { Expediente para la instalación de la Junta de Partido de Alcalá de } \\
\text { Henares }\end{array}$ & 1818 & \multirow{9}{*}{ leg. $642 / 1$} \\
\hline & División por partidos de la provincia de Madrid & $03 / 11 / 1817$ & \\
\hline & Modelo 2. Tarifa de las partes alícuotas & $30 / 11 / 1818$ & \\
\hline & Modelo 1. Tarifa de los precios medios & & \\
\hline & Miembros de la Junta de Partido de Alcalá de Henares & $13 / 09 / 1819$ & \\
\hline $\begin{array}{l}\text { Camarma de } \\
\text { Esteruelas }\end{array}$ & Cuaderno general de la riqueza & $20 / 12 / 1819$ & \\
\hline $\begin{array}{c}\text { Driebes } \\
\text { (Guadalajara) }\end{array}$ & $\begin{array}{l}\text { Diligencia para el perdón de la contribución por miseria de sus } \\
\text { vecinos como en Brea de Tajo y Mazuecos }\end{array}$ & $19 / 01 / 1819$ & \\
\hline Valverde Alcalá & Modelo 3. Resumen del pueblo & $24 / 01 / 1820$ & \\
\hline Meco & Modelo 3. Resumen del pueblo & $29 / 01 / 1820$ & \\
\hline
\end{tabular}




\begin{tabular}{|c|c|c|c|}
\hline \multicolumn{4}{|c|}{ Archivo Municipal de Chinchón } \\
\hline \multirow[t]{2}{*}{ Chinchón } & \multirow[t]{2}{*}{ Relaciones juradas de los bienes de los vecinos } & 1818 & $\begin{array}{l}\text { sigs. } 2431 \\
2432,2434, \\
2454,2480, \\
2526,2528, \\
2655,2656, \\
2657,5395, \\
5397 \text { y } 8068\end{array}$ \\
\hline & & 1817 & $\begin{array}{l}\text { sigs. } 2524 \\
2525 \text { y } 2527\end{array}$ \\
\hline $\begin{array}{l}\text { Partido de } \\
\text { Chinchón }\end{array}$ & $\begin{array}{l}\text { Correspondencia impresa del intendente provincial a la junta de } \\
\text { partido de Chinchón }\end{array}$ & 1818 & sig. 7629 \\
\hline Chinchón & Apeo y valuación general & $20 / 04 / 1819$ & $\begin{array}{c}\text { sigs. } 8067 \\
8072,8081 \\
8620,9059, \\
14589 \text { y } 10949\end{array}$ \\
\hline \multirow{2}{*}{$\begin{array}{l}\text { Partido de } \\
\text { Chinchón }\end{array}$} & Modelo 1. Tarifa de los precios medios & \multirow{2}{*}{$30 / 05 / 1818$} & \multirow{3}{*}{ sig. 8072} \\
\hline & Modelo 2. Tarifa de las partes alícuotas & & \\
\hline Chinchón & Cuaderno general de la riqueza & $07 / 08 / 1818$ & \\
\hline \multirow{4}{*}{$\begin{array}{l}\text { Partido de } \\
\text { Chinchón }\end{array}$} & Modelos impresos para la contribución general del reino & 1818 & sig. 8651 \\
\hline & $\begin{array}{l}\text { Documentos dirigidos a las juntas de contribución de partido y de la } \\
\qquad \text { villa de Chinchón }\end{array}$ & $1817 / 1819$ & $\begin{array}{c}\text { sigs. } 10931, \\
11779,12395 \\
\text { y } 15483\end{array}$ \\
\hline & $\begin{array}{l}\text { Correspondencia impresa del intendente provincial a la junta de } \\
\text { partido de Chinchón }\end{array}$ & 1817 & sig. 11468 \\
\hline & Órdenes y circulares impresas del intendente provincial de Madrid & 1817 & sig. 11559 \\
\hline Chinchón & $\begin{array}{l}\text { Modelo impreso de las relaciones juradas de los bienes de los } \\
\text { vecinos }\end{array}$ & 1817 & sig. 11561 \\
\hline Madrid & $\begin{array}{l}\begin{array}{l}\text { Vicente Jaudenes Nebot toma posesión como intendente provincial } \\
\text { de Madrid }\end{array}\end{array}$ & $23 / 01 / 1818$ & sig. 13063 \\
\hline \multirow{2}{*}{$\begin{array}{l}\text { Partido de } \\
\text { Chinchón }\end{array}$} & $\begin{array}{l}\text { La junta de partido de Chinchón recibe los modelos impresos para } \\
\text { redactar los cuadernos de la riqueza }\end{array}$ & 1818 & sig. 13933 \\
\hline & Reclamaciones ante la junta de partido de Chinchón & 1818 & sig. 14589 \\
\hline
\end{tabular}




\begin{tabular}{|c|c|c|c|}
\hline \multirow{2}{*}{ Arganda del Rey } & Modelo 3. Resumen del pueblo & $31 / 08 / 1818$ & \multirow{31}{*}{ sig. 17250} \\
\hline & Modelo 3. Resumen del pueblo. Verificado y rectificado & $13 / 03 / 1819$ & \\
\hline \multirow{2}{*}{ Belmonte de Tajo } & Modelo 3. Resumen del pueblo & $06 / 08 / 1818$ & \\
\hline & Modelo 3. Resumen del pueblo. Verificado y rectificado & $26 / 02 / 1819$ & \\
\hline \multirow{2}{*}{ Brea del Tajo } & Modelo 3. Resumen del pueblo & $23 / 06 / 1818$ & \\
\hline & Modelo 3. Resumen del pueblo. Verificado y rectificado & 03/03/1819 & \\
\hline \multirow{2}{*}{ Campo Real } & Modelo 3. Resumen del pueblo & 03/09/1818 & \\
\hline & Modelo 3. Resumen del pueblo. Verificado y rectificado & 04/03/1819 & \\
\hline \multirow{2}{*}{ Carabaña } & Modelo 3. Resumen del pueblo & $07 / 08 / 1818$ & \\
\hline & Modelo 3. Resumen del pueblo. Verificado y rectificado & 03/03/1819 & \\
\hline \multirow{2}{*}{ Chinchón } & Modelo 3. Resumen del pueblo & $12 / 08 / 1818$ & \\
\hline & Modelo 3. Resumen del pueblo. Verificado y rectificado & $09 / 03 / 1819$ & \\
\hline \multirow{2}{*}{$\begin{array}{c}\text { Driebes } \\
\text { (Guadalajara) }\end{array}$} & Modelo 3. Resumen del pueblo & $01 / 08 / 1818$ & \\
\hline & Modelo 3. Resumen del pueblo. Verificado y rectificado & 03/03/1819 & \\
\hline \multirow{2}{*}{$\begin{array}{c}\text { Mazuecos } \\
\text { (Guadalajara) }\end{array}$} & Modelo 3. Resumen del pueblo & $19 / 09 / 1818$ & \\
\hline & Modelo 3. Resumen del pueblo. Verificado y rectificado & 04/03/1819 & \\
\hline \multirow{2}{*}{ Morata de Tajuña } & Modelo 3. Resumen del pueblo & $12 / 08 / 1818$ & \\
\hline & Modelo 3. Resumen del pueblo. Verificado y rectificado & $04 / 03 / 1819$ & \\
\hline \multirow{2}{*}{ Orusco de Tajuña } & Modelo 3. Resumen del pueblo & $26 / 07 / 1818$ & \\
\hline & Modelo 3. Resumen del pueblo. Verificado y rectificado & 04/03/1819 & \\
\hline \multirow{2}{*}{ Perales de Tajuña } & Modelo 3. Resumen del pueblo & $02 / 09 / 1818$ & \\
\hline & Modelo 3. Resumen del pueblo. Verificado y rectificado & $26 / 02 / 1819$ & \\
\hline \multirow{2}{*}{ Tielmes } & Modelo 3. Resumen del pueblo & $03 / 09 / 1818$ & \\
\hline & Modelo 3. Resumen del pueblo. Verificado y rectificado & $26 / 02 / 1819$ & \\
\hline \multirow{2}{*}{$\begin{array}{l}\text { Titulcía (Bayona } \\
\text { de Tajuña) }\end{array}$} & Modelo 3. Resumen del pueblo & $31 / 08 / 1818$ & \\
\hline & Modelo 3. Resumen del pueblo. Verificado y rectificado & 05/03/1819 & \\
\hline \multirow{2}{*}{ Valdelagua } & Modelo 3. Resumen del pueblo & $10 / 08 / 1818$ & \\
\hline & Modelo 3. Resumen del pueblo. Verificado y rectificado & $11 / 03 / 1819$ & \\
\hline \multirow{2}{*}{ Valdilecha } & Modelo 3. Resumen del pueblo & $31 / 07 / 1818$ & \\
\hline & Modelo 3. Resumen del pueblo. Verificado y rectificado & $04 / 03 / 1819$ & \\
\hline $\begin{array}{l}\text { Partido de } \\
\text { Chinchón }\end{array}$ & Modelo 4. Resumen de la riqueza de los pueblos del partido & $17 / 03 / 1819$ & \\
\hline \multicolumn{4}{|c|}{ Archivo Regional de la Comunidad de Madrid } \\
\hline \multicolumn{4}{|c|}{ Archivo Municipal de Bustarviejo } \\
\hline \multirow{2}{*}{ Bustarviejo } & Apeo y valuación general & $08 / 12 / 1818$ & \multirow{4}{*}{ sig.160975/3 } \\
\hline & Cuaderno general de la riqueza & $--/--/ 1819$ & \\
\hline \multirow{2}{*}{$\begin{array}{l}\text { Partido de Pedraza } \\
\text { (Segovia) }\end{array}$} & Modelo 1. Tarifa de los precios medios & $24 / 12 / 1819$ & \\
\hline & Modelo 2. Tarifa de las partes alícuotas & & \\
\hline Bustarviejo & Cuaderno general de la riqueza & $01 / 02 / 1820$ & sig. $160975 / 4$ \\
\hline \multicolumn{4}{|c|}{ Archivo Municipal de Cabrera } \\
\hline Cabrera & Cuaderno general de la riqueza & $--/--/ 1818$ & sig. 136652/6 \\
\hline \multicolumn{4}{|c|}{ Archivo Municipal de Valdaracete } \\
\hline
\end{tabular}




\begin{tabular}{|c|c|c|c|}
\hline \multirow{6}{*}{ Valdaracete } & $\begin{array}{l}\text { Cuaderno de presupuestos que sirve de base para el catastro de la } \\
\text { villa (tasaciones de las tierras, ganados y edificios y producciones por } \\
\text { unidad de superficie) }\end{array}$ & 01/08/1819 & \multirow[t]{2}{*}{$\begin{array}{l}\text { sigs. } 214531 / 3 \\
\text { y } 214593 / 1\end{array}$} \\
\hline & Apeo y valuación general & $--/--/ 1820$ & \\
\hline & Relaciones juradas de los bienes de los vecinos & $1819 / 1820$ & sig. $214622 / 4$ \\
\hline & $\begin{array}{l}\text { Apeo y valuación general. Incluye las tasaciones de las tierras, los } \\
\text { ganados y los edificios }\end{array}$ & $--/--/ 1819$ & sig. $214592 / 1$ \\
\hline & $\begin{array}{l}\text { Declaraciones juradas de los contribuyentes de tierras, eras de pan, } \\
\text { viñas, olivos, zumacales, caballerías, edificios, fábricas, comercio, } \\
\text { censos, etc. }\end{array}$ & $1819 / 1820$ & \multirow[t]{2}{*}{$\begin{array}{l}\text { sigs. } 214603 \\
214612 \text { y } \\
219603\end{array}$} \\
\hline & Cuaderno general de la riqueza & $--/--/ 1820$ & \\
\hline \multicolumn{4}{|c|}{ Archivo Municipal de Fuentidueña de Tajo } \\
\hline \multirow{2}{*}{$\begin{array}{l}\text { Fuentidueña } \\
\text { de Tajo }\end{array}$} & Relaciones juradas de los bienes de los vecinos & $--/ 04 / 1818$ & sig. 13299 \\
\hline & $\begin{array}{l}\text { Declaraciones del maestro alarife relativa a la tasación de edificios } \\
\text { y solares }\end{array}$ & 12/07/1819 & sig. 13233 \\
\hline \multicolumn{4}{|c|}{ Archivo Municipal de Valdilecha } \\
\hline Valdilecha & Cuaderno general de la riqueza & $--/--/ 1818$ & sig. $17165 / 589$ \\
\hline \multicolumn{4}{|c|}{ Archivo Municipal de San Martín de la Vega } \\
\hline \multirow[t]{2}{*}{$\begin{array}{l}\text { San Martín } \\
\text { de la Vega }\end{array}$} & $\begin{array}{l}\text { Clasificación que hacen los peritos de las calidades de tierra y los tipos } \\
\text { de cultivos (rendimientos y costes de producción) para proceder a la } \\
\text { formación del cuaderno de la riqueza }\end{array}$ & $12 / 08 / 1818$ & \multirow[t]{2}{*}{$\begin{array}{l}\text { sigs. } 913644 \\
913646 \text { y } \\
913648\end{array}$} \\
\hline & Cuaderno general de la riqueza & $--/--/ 1819$ & \\
\hline \multicolumn{4}{|c|}{ Archivo Municipal de Villamanta } \\
\hline \multirow{5}{*}{ Villamanta } & Modelos de la contribución general del reino & $--/--1818$ & sig.17171/8 \\
\hline & Relaciones juradas de los bienes de los vecinos & $--/--/ 1817$ & sig. $17172 / 8$ \\
\hline & Cuaderno general de la riqueza & $14 / 08 / 1818$ & \multirow{5}{*}{$\begin{array}{l}\text { sigs. } 17172 / 26 \\
\text { y } 17207 / 701\end{array}$} \\
\hline & $\begin{array}{c}\text { Certificaciones sobre el estado de las cepas y cuentas de los frutos } \\
\text { pontificales }\end{array}$ & $--/--/ 1817$ & \\
\hline & $\begin{array}{l}\text { Relaciones de los productos agrícolas que los vecinos de Méntrida } \\
\text { cosecharon en Villamanta }\end{array}$ & $--/--/ 1818$ & \\
\hline \multirow{2}{*}{$\begin{array}{l}\text { Partido de } \\
\text { Navalcarnero }\end{array}$} & Modelo 1. Tarifa de los precios medios & 07/04/1818 & \\
\hline & Modelo 2. Tarifa de las partes alícuotas & 23/04/1818 & \\
\hline \multirow{3}{*}{ Villamanta } & Modelo 3. Resumen del cuaderno & 18/08/1818 & \multirow{2}{*}{ sig. $17173 / 55$} \\
\hline & Modelo 3. Resumen del cuaderno & $--/ 12 / 1820$ & \\
\hline & Relaciones juradas de los bienes de los vecinos & $1817 / 1818$ & \multirow{5}{*}{ sig. $17172 / 30$} \\
\hline Casarrubuelos & Relaciones juradas de los bienes de los vecinos & $1817 / 1818$ & \\
\hline Navalcarnero & Relaciones juradas de los bienes de los vecinos & $1817 / 1818$ & \\
\hline Méntrida (Toledo) & Relaciones juradas de los bienes de los vecinos & $1817 / 1818$ & \\
\hline $\begin{array}{l}\text { Valmojado } \\
\text { (Toledo) }\end{array}$ & Relaciones juradas de los bienes de los vecinos & $1817 / 1818$ & \\
\hline
\end{tabular}




\begin{tabular}{|c|c|c|c|}
\hline \multirow{3}{*}{ Partido de Getafe } & Modelo 1. Tarifa de los precios medios & 07/04/1818 & \multirow{7}{*}{$\begin{array}{l}\text { sigs. } 17485 \text { y } \\
17486\end{array}$} \\
\hline & Modelo 2. Tarifa de las partes alícuotas & 23/04/1818 & \\
\hline & Modelo 4. Resumen del partido de Getafe & $--/--/ 1818$ & \\
\hline \multirow{4}{*}{$\begin{array}{l}\text { Serranillos } \\
\text { del Valle }\end{array}$} & Modelos para la contribución general del reino & 1818 & \\
\hline & Cuaderno general de la riqueza & 22/08/1818 & \\
\hline & Modelo 3. Resumen del cuaderno & $26 / 08 / 1818$ & \\
\hline & Modelo 3. Resumen del cuaderno & $18 / 09 / 1820$ & \\
\hline \multicolumn{4}{|c|}{ Archivo Municipal de Carabaña } \\
\hline \multirow{3}{*}{$\begin{array}{l}\text { Partido de } \\
\text { Chinchón }\end{array}$} & Modelo 1. Tarifa de los precios medios & $--/--/ 1819$ & \multirow{10}{*}{$\begin{array}{l}\text { sigs. } 16871 \text { y } \\
16895\end{array}$} \\
\hline & Modelo 2. Tarifa de las partes alícuotas & $--/--/ 1819$ & \\
\hline & $\begin{array}{l}\text { Tabla de las producciones medias de cada cultivo por unidad de } \\
\text { superficie }\end{array}$ & $--/ 02 / 1819$ & \\
\hline \multirow{7}{*}{ Carabaña } & Modelo 3. Resumen del cuaderno & $07 / 08 / 1818$ & \\
\hline & Modelo 3. Resumen del cuaderno & 03/03/1819 & \\
\hline & Modelo 3. Resumen del cuaderno & $30 / 01 / 1820$ & \\
\hline & Rectificación del resumen del cuaderno & 23/09/1820 & \\
\hline & Rectificación del resumen del cuaderno & $26 / 10 / 1820$ & \\
\hline & Rectificación del resumen del cuaderno & $03 / 11 / 1820$ & \\
\hline & Cuaderno general de la riqueza & 05/01/1820 & \\
\hline \multicolumn{4}{|c|}{ Archivo Municipal de Loeches } \\
\hline \multirow{4}{*}{ Loeches } & Modelo 3. Resumen del cuaderno & 19/07/1818 & sig. 96139/21 \\
\hline & Modelo 3. Resumen del cuaderno & $27 / 10 / 1820$ & sig. 96139/22 \\
\hline & Cuaderno general de la riqueza & 22/08/1819 & sig. 96139/25 \\
\hline & Cuaderno general de la riqueza & $22 / 09 / 1820$ & \multirow{3}{*}{ sig. 96139/26 } \\
\hline \multirow{2}{*}{$\begin{array}{c}\text { Partido de } \\
\text { Almonacid Zorita }\end{array}$} & Modelo 1. Tarifa de los precios medios & 29/04/1818 & \\
\hline & Modelo 2. Tarifa de las partes alícuotas & 29/04/1818 & \\
\hline \multicolumn{4}{|c|}{ Archivo Municipal de Rascafría } \\
\hline \multirow{2}{*}{$\begin{array}{l}\text { Rascafría } \\
\text { y el Paular }\end{array}$} & Cuaderno general de la riqueza & $20 / 08 / 1818$ & \multirow{2}{*}{ sig. $88671 / 6$} \\
\hline & Cuaderno general de la riqueza & $01 / 02 / 1820$ & \\
\hline \multicolumn{4}{|c|}{ Archivo Municipal de Paracuellos del Jarama } \\
\hline \multirow{2}{*}{$\begin{array}{l}\text { Paracuellos } \\
\text { del Jarama }\end{array}$} & Apeo y valuación general & $30 / 08 / 1819$ & sig. 913444/1 \\
\hline & Relaciones juradas de los bienes de los vecinos & $--/--/ 1819$ & sig. $14727 / 7$ \\
\hline \multicolumn{4}{|c|}{ Archivo Municipal de Camarma de Esteruelas } \\
\hline $\begin{array}{l}\text { Camarma de } \\
\text { Esteruelas }\end{array}$ & Cuaderno general de la riqueza & 03/09/1818 & sig.75878 \\
\hline \multicolumn{4}{|c|}{ Archivo Municipal de Villaconejos } \\
\hline Villaconejos & Apeo y valuación general & $--/--/ 1820$ & sig. 17827 \\
\hline
\end{tabular}

